Artigo Teórico-empírico

\section{Antecedentes do Compromisso com as Metas Orçamentárias}

\author{
Antecedents of Commitment to Budgetary Goals
}

\author{
Daniele Cristina Bernd*1 $\odot$ \\ Ilse Maria Beuren ${ }^{1} \odot$ \\ Celliane Ferraz Pazetto ${ }^{10}$ \\ Carlos Eduardo Facin Lavarda' ${ }^{10}$
}

\section{RESUMO}

Objetivo: este estudo analisa as interaçóes entre a participação orçamentária, a motivação no trabalho (intrínseca e extrínseca) e o compromisso com as metas orçamentárias. Métodos: uma survey foi realizada com 131 gestores de nível intermediário de diferentes áreas organizacionais de empresas classificadas entre as melhores e maiores empresas do Brasil. Resultados: os resultados da modelagem de equaçóes estruturais indicam que as motivaçóes intrínsecas e extrínsecas apresentam papéis distintos em suas interaçóes com a participação orçamentária e o compromisso com as metas. E o envolvimento destes com o processo orçamentário revela efeitos comportamentais e motivacionais. Conclusóes: conclui-se que a participaçáo no processo orçamentário pode refletir positivamente no desempenho gerencial, na medida em que é capaz de desencadear efeito motivacional intrínseco e favorecer comportamentos voltados ao compromisso com as metas orçamentárias.

Palavras-chave: participação orçamentária; motivação no trabalho; compromisso com as metas orçamentárias.

\footnotetext{
* Autora Correspondente.

1. Universidade Federal de Santa Catarina, Programa de Pós-graduação em Contabilidade, Florianópolis, SC, Brasil.
}

Como citar: Bernd, D. C., Beuren, I. M., Pazetto, C. F., \& Lavarda, C. E. F. (2022). Antecedentes do compromisso com as metas orçamentárias. Revista de Administração Contemporânea, 26(2), e200018. https://doi.org/10.1590/1982-7849rac2022200018.por

\section{ABSTRACT}

Objective: this study analyzes the interactions between budgetary participation, motivation at work (intrinsic and extrinsic), and commitment to budgetary goals. Methods: a survey was carried out with 131 intermediate level managers from different organizational areas of companies classified among the best and biggest companies in Brazil. Results: the results of modeling structural equations indicate that intrinsic and extrinsic motivations have different roles in their interactions with budgetary participation and commitment to goals. And their involvement in the budgetary process reveals behavioral and motivational effects. Conclusions: it is concluded that participation in the budgetary process can positively reflect on managerial performance, insofar as it is able to trigger intrinsic motivational effect and favor behaviors aimed at the commitment to budgetary goals.

Keywords: budgetary participation; motivation at work; commitment to budgetary goals.
Classificação JEL: M410, M120.

Editor-chefe: Wesley Mendes-da-Silva (Fundação Getulio Vargas, EAESP, Brasil) (a) Pareceristas: Renata Braga Berenguer de Vasconcelos (Universidade Federal de Pernambuco, Brasil)
Cristina Viana de Jesus (Universidade Federal de Santa Catarina, PPGC, Brasil) Pareceristas: Renata Braga Berenguer de Vasconcelos (Universidade Federal de Pernambuco, Brasil) (1)
Cristina Viana de Jesus (Universidade Federal de Santa Catarina, PPGC, Brasil) (6) Relatório de Revisão por Pares: $O$ Relatório de Revisão por Pares está disponivel neste link externo. Aceite em: 13/04/2021

$\begin{array}{llllll}3 & 4 & 5 & 6 & 7 & 8 \\ x & x & x & x & x & x\end{array}$




\section{INTRODUÇÃO}

O orçamento é um instrumento comumente utilizado para o controle gerencial (Frezatti, 2009), devido à sua significante contribuiçáo para avaliar o desempenho gerencial e influenciar as atitudes e comportamentos dos indivíduos no ambiente de trabalho (Covaleski, Evans III, Luft, \& Shields, 2007), proporcionando distintas reaçóes e interaçôes humanas (Milani, 1975), as quais podem implicar maiores esforços para o alcance de metas orçamentárias (Jacomossi, Schlup, \& Zonatto, 2018; Lunardi, Zonatto, \& Nascimento, 2020; Milani, 1975; Shields \& Shields, 1998). Assim, uma maneira de aumentar a eficácia do orçamento é propiciar um incremento da participação orçamentária dos gestores (Hassel \& Cunningham, 1993).

A participação no processo orçamentário, dada a sua capacidade de influenciar a cogniçấo e a motivação dos subordinados (Chong, Eggleton, \& Leong, 2005) e exercer função informacional nas organizaçōes (Maiga, 2005), pode levar a uma melhora atitudinal no âmbito laboral (Milani, 1975). A participação orçamentária pode se refletir em maior satisfação com suas atividades e maior compromisso com as metas orçamentárias (Maiga, 2005), e um melhor desempenho (Derfuss, 2016; Jacomossi et al., 2018; Kren \& Liao, 1988; Lunardi et al., 2020; Mia, 1988; Nouri \& Parker, 1998; Shields \& Shields, 1998).

Embora a pesquisa sobre a influência da participaçáo orçamentária no desempenho se estenda por várias décadas (Stearns, 2016), ao explorar essas interaçóes (ex.: Chong \& Johnson, 2007; Dani, Zonatto, \& Diehl, 2017; Derfuss, 2016; Isgiyarta, Nugroho, Ratmono, Helmina, \& Pamungkas, 2019; Stearns, 2016) evidencia resultados mistos, controversos ou inconsistentes. Isso sugere que essa relaçáo pode ser influenciada por outros estados mentais ou cognitivos dos indivíduos (Covaleski et al., 2007). Justificase assim a inclusão de outras variáveis intervenientes (Nouri \& Parker, 1998) que possam auxiliar na explicação dos efeitos psicológicos e comportamentais associados, como é o caso da motivação (Baerdemaeker \& Bruggeman, 2015; Brownell \& McInnes, 1986) e do compromisso com as metas (Kyj \& Parker, 2008; Nouri \& Parker, 1998; Parker \& Kyj, 2006; Wentzel, 2002), além de explicar os resultados conflitantes da análise direta dessa interação (Dani et al., 2017; Derfuss, 2016).

A questão motivacional no trabalho é um dos efeitos psicológicos que podem advir da participação orçamentária (Chong et al., 2005; Shields \& Shields, 1998). A motivação é capaz de estimular a dedicação necessária para a realização ou alcance de uma meta, encorajando ou incentivando os funcionários (intrínseca ou extrinsecamente) ao trabalho. Portanto, a motivação dos funcionários é considerada um fator decisivo nas organizaçóes, capaz de influenciar positivamente o desempenho organizacional, na medida em que pode direcionar os indivíduos a atuarem em busca do alcance das metas (Locke \& Latham, 1990).

A literatura sobre orçamentos mostra que a motivação pode influenciar o comportamento das pessoas no cumprimento das metas orçamentárias (Stearns, 2016), e se desenvolver a partir da possibilidade de participaçáo na decisão relacionada às estimativas das metas orçamentárias (Chong \& Johnson, 2007; Baerdemaeker \& Bruggeman, 2015). Estudos prévios sugerem que a motivação pode atuar tanto de forma direta sobre os esforços à realização do orçamento (Brownell \& McInnes, 1986) quanto de forma indireta (efeito interveniente) (Mia, 1988). No entanto, o seu papel motivacional entre a participação orçamentária e os resultados é inconsistente (Santos, Lavarda, \& Marcello, 2014).

A literatura orçamentária pouco tem abordado os efeitos da motivação no trabalho e seus impactos na execução de suas tarefas (Lau \& Roopnarain, 2014), assim como os tipos motivacionais dos funcionários (Gómez-Ruiz \& Rodríguez-Rivero, 2018; Van der Kolk, Van Veen-Dirks, \& Bogt, 2018; Wong-On-Wing, Guo, \& Lui, 2010). Além disso, escassos são os estudos sobre a motivação extrínseca (incentivos tangíveis), que decorre de estímulos subjacentes (ex.: remuneração, bônus), e a motivação intrínseca (incentivos intangíveis), alcançada por meio de estímulos não remuneratórios (ex.: reconhecimento social) (Deci \& Ryan, 1985; Kuvaas, Buch, Weibel, Dysvik, \& Nerstad, 2017). São lacunas que permanecem em aberto ao demonstrar os respectivos papéis e interaçóes de cada subtipo motivacional (Kuvaas et al., 2017), com a participação e o compromisso com as metas orçamentárias.

De acordo com Welsh, Baer, Sessions e Garud (2020), indivíduos comprometidos com uma meta, em geral, tendem a estar motivados para evitar o fracasso em atingir essa meta. Isso ocorre porque os resultados esperados, decorrentes do estabelecimento de metas, ocorrem por meio de processos cognitivos. Esse fator demonstra a relevância da abordagem dos processos cognitivos que motivam o comportamento (Welsh, Baer, Sessions, \& Garud, 2020) e que buscam identificar quais fatores influenciam o compromisso com as metas, visto que esses fatores podem ter implicaçóes críticas em suas definiçốes (Hassel \& Cunningham, 1993).

Diante desse contexto, tem-se a seguinte questão de pesquisa: Quais os efeitos das interaçóes entre a participação orçamentária, a motivação no trabalho (intrínseca e extrínseca) e o compromisso com as metas orçamentárias? Assim, o estudo objetiva analisar as interaçóes entre a participação orçamentária, a motivação no trabalho (intrínseca e extrínseca) e o compromisso com as metas orçamentárias. Para tanto, analisam-se os efeitos diretos entre as variáveis e o efeito indireto (mediação) da 
motivação, tal como Sholihin, Pike, Mangena e Li (2011). Neste estudo, a motivação é compreendida como um aspecto psicológico (socioafetivo) (Wong-On-Wing et al., 2010), capaz de influenciar o seu comportamento em relação às metas orçamentárias. Sugere-se que os efeitos motivacionais podem ser decorrentes da possibilidade de os subordinados poderem participar ativamente no processo orçamentário. Dessa maneira, tanto a participação quanto a motivação podem diretamente levar a diferentes níveis de compromisso com as metas, uma vez que os indivíduos podem perceber essas experiências de forma diferente (Stearns, 2016).

Os funcionários que têm a oportunidade de participar do processo de elaboraçáo do orçamento podem sentir que suas necessidades psicológicas básicas, inerentes a todos os seres humanos, conforme preconiza a teoria da autodeterminação (SDT), foram atendidas (autonomia, competência e interconexão/relacionamentos) (Baerdemaeker \& Bruggeman, 2015). Isso pode gerar motivação para que eles cumpram suas metas. Essa motivação pode também auxiliá-los a ter um comportamento mais positivo com o processo orçamentário, como, por exemplo, por meio de melhor aceitação e execução do orçamento elaborado e compartilhado, apresentando maior comprometimento (Wafiroh, Abdani, \& Nurdin, 2020).

Os achados desta pesquisa revelam que a motivação é um construto multidimensional e que os indivíduos podem experimentar este estado de diferentes maneiras (Deci \& Ryan, 1985; Ryan \& Deci, 2000) frente às oportunidades de envolvimento orçamentário e a importância das metas para elas (Reid, 2002). A motivaçáo atua como um estímulo que pode direcionar os indivíduos a atuarem na direçáo de seus objetivos e manifestar-se na gestão (Lau \& Roopnarain, 2014) a partir da participação orçamentária. Além disso, a participaçáo per si, direta e indiretamente, conduz a um maior compromisso com as metas orçamentárias.

Contribui-se empiricamente para o fluxo da pesquisa sobre o processo orçamentário ao aprofundar a compreensão dos fatores antecedentes que podem impulsionar o compromisso dos gestores com as metas orçamentárias. Demonstra-se, por meio de uma abordagem comportamental, os mecanismos cognitivos e motivacionais que podem estar relacionados ao desempenho do funcionário (Locke, Motowidlo, \& Bobko, 1986; Murray, 1990), em particular com suas metas, bem como ao potencial motivacional e comportamental atrelado ao orçamento (Argyris, 1952) e à participação orçamentária.

Ainda, contribui-se para as discussōes recentes da contabilidade que postulam diferenças entre os tipos de motivaçáo para entender como os distintos controles gerenciais podem influenciar o desempenho dos funcionários (Baerdemaeker \& Bruggeman, 2015; Gómez-Ruiz \& Rodríguez-Rivero, 2018; Wong-On-Wing et al., 2010).
Já para a prática da contabilidade gerencial, os resultados contribuem ao destacar a importância de variáveis individuais (Baerdemaeker \& Bruggeman, 2015) que auxiliam a compreender aspectos psicológicos e comportamentais relacionados ao processo orçamentário dos gestores, por meio do compromisso com as metas orçamentárias e pela motivação no trabalho.

\section{FUNDAMENTAÇÃO TEÓRICA}

\section{Participação orçamentária}

Um sistema orçamentário que permite aos gestores participar e serem responsáveis pelo processo de preparação do orçamento e definiçấo de metas pode ser positivo para a organização. A literatura destaca dentre os reflexos positivos: o aumento de atitudes positivas e o aumento do desempenho no trabalho (Argyris, 1952; Jacomossi et al., 2018; Lunardi et al., 2020; Mia, 1988; Nouri \& Parker, 1998), o compartilhamento de informações (Kyj \& Parker, 2008; Lunardi et al., 2020; Shields \& Shields, 1998), a satisfação do funcionário (Chong et al., 2005; Kyj \& Parker, 2008; Zonatto, Nascimento, Lunardi, \& Degenhart, 2020), a percepção de justiça organizacional (Derfuss, 2009; Kyj \& Parker, 2008; Sholihin, Pike, Mangena, \& Li, 2011; Wentzel, 2002), a comunicação aberta e a interação com o funcionário (Lavarda \& Almeida, 2013), a motivação (Kyj \& Parker, 2008), e a definição de metas orçamentárias (Hassel \& Cunningham, 1996; Maiga, 2005; Milani, 1975).

Embora a literatura gerencial há décadas venha tentando compreender os resultados conflitantes da interação direta da participação orçamentária com o desempenho (dos funcionários, gerencial e organizacional), ainda se observam lacunas (Dani et al., 2017; Derfuss, 2016), principalmente atreladas à identificação de fatores psicológicos e cognitivos que possam ajudar a explicar essas interaçôes. Ademais, reconhece-se que outras variáveis podem atuar de maneira interveniente (Mia, 1988; Nouri \& Parker, 1998) e auxiliar a melhor compreender essas relaçôes.

Pesquisadores propóem que o envolvimento dos funcionários na tomada de decisóes possibilita um maior compromisso com a organização em que trabalham (Parker \& Kyj, 2006). Ao fomentar a comunicação entre os diferentes níveis organizacionais e estimular a cooperação e a comunicação intraorganizacional (Brownell \& McInnes, 1986), a participação do funcionário no processo orçamentário pode influenciar o processo e a definiçâao de metas orçamentárias (Hassel \& Cunningham, 1996; Maiga, 2005; Milani, 1975) e se refletir em maior compromisso com o alcance destas (Almasi, Palizdar, \& Parsian, 2015; Nouri \& Parker, 1998; Subramaniam \& Mia, 2001; Wong-On-Wing et al., 2010). Por sua vez, maior comprometimento influencia 
o desempenho (Badu, Awaluddin, \& Mas'ud, 2019; Nouri \& Parker, 1998).

Da mesma maneira, reconhece-se que existem benefícios cognitivos decorrentes da participação orçamentária de gestores (Hassel \& Cunningham, 1993). Maior envolvimento pode aumentar a confiança e fomentar sentimentos de realização, senso de satisfação pessoal, sentimento de pertencimento e maior identificação com a organizaçáo (Wong-On-Wing et al., 2010). Quando existe abertura para uma comunicação efetiva na organização, além de o indivíduo adquirir aprimoramento, pode fortalecer suas relaçóes com a empresa. A participação ativa em discussóes sobre questóes organizacionais e nas tomadas de decisões pode levar o indivíduo a se considerar um membro importante da organização e promover sentimentos de autoestima por ser ouvido (Maiga, 2005). Com isso, a participação orçamentária pode influenciar as açôes desses funcionários (Birnberg, Luft, \& Shields, 2007) ao estimular a motivação no trabalho. Como resultado de uma maior motivação, também haverá reflexos positivos no desempenho.

Nesta pesquisa, portanto, a participação orçamentária é analisada como sendo capaz de influenciar diferentemente os indivíduos envolvidos (Birnberg et al., 2007; Covaleski et al., 2007), e isso pode refletir no seu desempenho gerencial (Brownell \& McInnes, 1986; Jacomossi et al., 2018; Lunardi et al., 2020). A partir da abordagem comportamental (individual), analisa-se de que forma a participaçáo orçamentária está relacionada a comportamentos individuais, tal como o compromisso com o desempenho atrelado às metas orçamentárias, e a estímulos motivacionais, decorrentes da motivação no trabalho (Brownell \& McInnes, 1986; Lau \& Buckland, 2001; Murray, 1990; Shields \& Shields, 1998).

\section{Participação orçamentária e motivação no trabalho}

A motivação é considerada uma força que induz a açáo do indivíduo, com implicaçóes na forma, direçáo, intensidade e duraçáo do comportamento (Meyer, Becker, \& Vandenberghe, 2004). Para Locke e Latham (2004), a motivação consiste de "fatores internos que impulsionam a ação e os fatores externos que podem atuar como incentivos à ação" (Locke \& Latham, 2004, p. 48). Esses fatores são denominados de motivação intrínseca e extrínseca. Segundo Deci, Connell e Ryan (1989) e Vallerand (1997), entendese por motivaçáo intrínseca aquele desejo individual, ou próprio em si, de realizar uma atividade sem solicitaçóes, experimentando prazer e satisfação inerentes às atividades e em realizá-las. A motivação intrínseca se relaciona com efeitos positivos organizacionais, tais como envolvimento no trabalho, identificação da tarefa e produtividade dos funcionários (Pinder, 2011). Já a motivação extrínseca pode ser compreendida como o desejo de realizar uma atividade com a intenção de alcançar um benefício (incentivo, recompensa) ou evitar um resultado negativo (punição) (Deci, Connell, \& Ryan, 1989; Vallerand, 1997).

O estímulo à participação orçamentária relaciona-se aos efeitos motivacionais (Reid, 2002), por influenciar na alocaçáo, direçáo e persistência de seus esforços no trabalho (Birnberg et al., 2007). A participação orçamentária promove atitudes positivas nos funcionários, motiva-os (Shields \& Shields, 1998) e permite que se envolvam ativamente no orçamento e nas metas (Reid, 2002). Reid (2002) destaca que a participação de fato pode resultar no empoderamento dos funcionários de baixo para cima, devido ao acesso a informaçóes e incentivos que podem ser usados em conjunto com os conhecimentos sobre os fundamentos da organização para assegurar o cumprimento de seus objetivos.

Os resultados do estudo de Wong-On-Wing, Guo e Lui (2010) sugerem que os indivíduos podem ser motivados, tanto intrinsecamente quanto extrinsecamente, para participar do processo orçamentário. Decorre que a participação, além de efeitos nos resultados e recompensas, influencia nas representaçóes mentais individuais por processos psicológicos, como a definição de metas, nível de aspiração, estresse e justiça (Birnberg et al., 2007).

Macinati e Rizzo (2014) aduzem que a participação orçamentária desencadeia efeitos motivacionais devido à oportunidade de participar do processo de definição do orçamento. Isso melhora o senso de controle, confiança e identificaçáo dos funcionários com a organização. Embora Mia (1989) tenha indicado que as interaçōes entre a participação orçamentária e a motivação apresentam resultados divergentes (positivos, negativos, significativos e não significativos), a participação no orçamento é capaz de apresentar impacto positivo na motivação dos funcionários, aumentando a quantidade e a qualidade da produção e a cooperação entre os gestores (Djalil, Indriani, \& Muttaqin, 2017).

Baerdemaeker e Bruggeman (2015) demonstram que um maior nível de participação orçamentária aumenta a motivação autônoma dos gestores. Assim, participar do processo de preparaçáa do orçamento pode influenciar diretamente na motivação dos funcionários. Espera-se que a participaçáo no orçamento possa proporcionar o alcance das necessidades psicológicas básicas dos funcionários (Deci \& Ryan, 1985). Tal como Van der Kolk, Van Veen-Dirks e Bogt (2019), espera-se que a motivação seja fomentada por um ambiente de suporte que possa: (a) evocar sentimentos de competência, ao possibilitar o envolvimento no orçamento; (b) fornecer um senso de autonomia, ao permitir que o funcionário expresse opinióes e participe de escolhas; e (c) cumprir as necessidades de relacionamentos, ao ser ouvido por seus pares. 
Assim, à luz da teoria da autodeterminação se reconhece que os gestores apresentarão qualidades aprimoradas de motivação para o trabalho, na proporção em que se identificarem com o valor e a importância de seu trabalho (Deci, Olafsen, \& Ryan, 2017). Defende-se que os indivíduos, ao participarem efetivamente da definição de metas, valorizarão a participação em si e atribuirão sentimentos de realização (motivaçáo intrínseca). Porém, é possível que os funcionários obtenham mais informaçóes, por meio da comunicação, e que isso envolva a oferta de recompensas atreladas ao seu desempenho. Isso pode levar o indivíduo a atribuir significados diferentes a essas tarefas, com maior ênfase no desempenho e competência (Lau \& Roopnarain, 2014). Assim, formula-se a primeira hipótese:

H1: A participação orçamentária influencia positivamente a motivação intrínseca $\left(\mathrm{H}_{1 \mathrm{a}}\right)$ e a motivação extrínseca $\left(\mathrm{H}_{1 \mathrm{~b}}\right)$ no trabalho.

\section{Motivação no trabalho e compromisso com as metas orçamentárias}

O compromisso é uma força que une um indivíduo a um curso de ação para um alvo específico (Meyer \& Herscovitch, 2001). Esse compromisso está atrelado a um fator motivacional e pode assumir diferentes formas e ser direcionado para diferentes focos (Meyer et al., 2004), como o compromisso com as metas orçamentárias. É entendido como a determinaçáo de tentar alcançar um objetivo (meta) e a persistência de persegui-lo ao longo do tempo (Chong \& Chong, 2002; Locke \& Latham, 1990).

Mathieu e Zajac (1990) destacam que o compromisso de metas orçamentárias apoia aspectos psicológicos, que envolvem fatores individuais, profissionais e organizacionais, e inclui avaliações, sentimentos, emoçóes e tendências de ação específicas para os indivíduos sob observação. Kren (1992) aponta que o compromisso com as metas atua mobilizando esforços e aumenta a persistência no seu alcance. GómezMiñambres (2012) explica que o compromisso com as metas pode ser determinado pela interação entre metas e padrões de referências individuais, em que referências mais altas exigem metas elevadas para que se assuma maior compromisso com as metas. Locke e Latham (2002) advertem que, para que exista um compromisso com as metas, os indivíduos devem sentir-se motivados.

À luz da teoria da autodeterminação, sugere-se que os indivíduos irão apresentar determinados comportamentos porque existe uma motivaçáo por trás de seu comportamento. Assim, diferentes motivaçóes irão se refletir de maneira distinta nos comportamentos dos indivíduos, já que a motivação é decorrente do impulso dentro de si para fazer algo (Ryan \& Deci, 2000). Kuvaas, Buch, Weibel, Dysvik e Nerstad (2017) e Van der Kolk, Van Veen-Dirks e Bogt (2019) advertem que as motivações intrínseca e extrínseca demonstram efeitos diferentes nos resultados dos empregados e devem ser abordadas separadamente.

Gómez-Ruiz e Rodríguez-Rivero (2018) aduzem que a participação consultiva dos funcionários aumenta a motivação autônoma (próxima da motivação intrínseca), enquanto a pseudoparticipação a diminui. Van der Kolk et al. (2019) apontam que as motivaçóes intrínseca e extrínseca estão positivamente associadas ao desempenho departamental. Já as motivaçóes (intrínseca e extrínseca) medeiam a relação entre os controles gerenciais e o desempenho; no entanto, se relacionam diferentemente com os controles e com o desempenho. Isso sugere que o comportamento dos gestores em relação ao seu compromisso com as metas orçamentárias pode ser influenciado de forma diferente pela motivação intrínseca e pela motivação extrínseca.

O estudo de Ke e Zhang (2009) identificou que tanto a motivação intrínseca quanto a extrínseca se relacionam de maneira positiva e significativa com o compromisso com as metas orçamentárias. Subramaniam e Mia (2001) descrevem que o compromisso dos indivíduos com as metas se relaciona com fatores extrínsecos e intrínsecos. Cada um desses elementos exige açóes dos indivíduos para o alcance das metas, e se estão motivados (intrínseca ou extrinsecamente) a realizá-las, tentam cumpri-las (Meyer et al., 2004).

A motivação intrínseca é capaz de determinar a direção do comportamento do indivíduo, bem como o nível de esforço e de persistência diante de obstáculos, decorrente da necessidade de autodeterminação e competência (Deci \& Ryan, 1985). A motivação intrínseca estimula o indivíduo a se comprometer mais com a meta ou objetivo (Ke \& Zhang, 2009). O estudo de Gómez-Miñambres (2012) apontou que as interações entre as metas e a motivação intrínseca são diferentes das interaçóes extrínsecas, sendo que os indivíduos, ao se preocuparem com a definição de metas e alcançá-las, criam um senso de realização. Assim, formula-se a hipótese:

H2a: A motivação intrínseca no trabalho atua positivamente sobre o compromisso com as metas orçamentárias.

De acordo com a teoria da autodeterminação, os incentivos externos afetam positivamente o compromisso com as metas (Deci \& Ryan, 2000). Locke e Latham (2002) destacam que usar incentivos externos pode ser uma alternativa para aumentar o compromisso com as metas, uma vez que a remuneraçáo se relaciona com o compromisso de o funcionário permanecer na organização por conta de vantagens como salários e outros benefícios (Allen $\&$ Meyer, 1993). Com isso, presume-se que a motivação extrínseca pode levar os indivíduos a trabalhar com maior 
intensidade para obter as recompensas esperadas, tais como oportunidades de carreira e ganhos financeiros (Ke \& Zhang, 2009). Argumenta-se que a motivação extrínseca pode manter os indivíduos mais comprometidos com a tarefa, e que aumenta a importância de se sair bem, já que as recompensas estarão atreladas ao seu desempenho (Ryan \& Deci, 2000). Esses argumentos sugerem a hipótese:

H2b: A motivação extrínseca no trabalho atua positivamente sobre o compromisso com as metas orçamentárias.

\section{Papel mediador da motivação no trabalho}

A relação entre a participação orçamentária e o desempenho gerencial tem sido amplamente explorada na contabilidade gerencial e vem evidenciando resultados positivos (Argyris, 1952; Badu et al., 2019; Brownell \& McInnes, 1986; Dani et al., 2017; Derfuss, 2016; Mia, 1989; Nouri \& Parker, 1998; Rachman, 2014; Wong-On-Wing et al., 2010; Zonatto, Weber, \& Nascimento, 2019). A literatura que explora a participação orçamentária também reconhece interaçóes diretas e positivas com comprometimento organizacional (Baerdemaeker \& Bruggeman, 2015; Subramaniam \& Mia, 2001) e com o compromisso de metas (Chong \& Chong, 2002; Chong \& Johnson, 2007; Chong \& Tak-Wing, 2003; Kren \& Liao, 1988; Lavarda, Sant’ana, Manfroi, \& Dagostini, 2015; Macinati \& Rizzo, 2014; Wentzel, 2002).

A teoria do estabelecimento de metas pode ajudar a explicar essa relação ao enfatizar a necessidade de constatar o efeito do estabelecimento de metas organizacionais no trabalho de cada funcionário (Locke \& Latham, 1990). Também pode ajudar a explicar que quanto maior for a participação dos funcionários no processo orçamentário, maior será o comprometimento na realização das tarefas e no desempenho de sua função (Isgiyarta et al., 2019). Decorre que a participação pode proporcionar mecanismos motivacionais e cognitivos (Birnberg et al., 2007; Reid, 2002), com reflexos atitudinais e comportamentais (Maiga, 2005).

Com isso, pode-se fomentar o sentimento de pertencimento (Shields \& Shields, 1998), assim como sentimentos de autovalorização, influência e envolvimento (aspectos motivacionais) em decisões orçamentárias (Maiga, 2005), além de promover um senso de equidade (Wentzel, 2002). Todos esses fatores podem afetar positivamente o comprometimento do funcionário e seu atendimento às metas orçamentárias (Lavarda et al., 2015). Inclusive, pode levar os gestores a definir metas mais difíceis (Kren \& Liao, 1988; Locke \& Latham, 1990).

Embora a literatura tenha apresentado evidências de diversos efeitos da participação orçamentária nas atitudes e no comportamento dos gestores, Lau e Tan (2006) ressaltam que essas interaçôes não são simples. Em geral, são explicadas por outras variáveis mediadoras ou moderadoras (Covaleski et al., 2007; Derfuss, 2016), como a motivação (Baerdemaeker \& Bruggeman, 2015; Brownell \& McInnes, 1986). GómezRuiz e Rodríguez-Rivero (2018), ao analisarem o efeito da motivação dos funcionários, como mediadora da relaçâo entre a participação consultiva e o desempenho, constataram que a motivação autônoma medeia essa relação; no entanto, a motivação controlada não. Isso sugere que a relação direta entre a participação dos funcionários pode ser explicada (indiretamente) pela questáo motivacional.

A participação orçamentária pode desencadear aumento do comprometimento afetivo dos funcionários ao valorizar sua interação, assim que este realizar uma avaliação com seu envolvimento e influência na meta orçamentária (Stearns, 2016). Com isso, os funcionários poderão sentir maior vínculo emocional com a organização e maior motivação para atingir suas metas (Baerdemaeker \& Bruggeman, 2015). Wong-OnWing et al. (2010) apontam que empregados podem se sentir intrinsecamente motivados na participação da definiçẫo de metas, principalmente quando objetivam obter realizaçóes e satisfaçôes individuais como resultado do seu ato. Esse fator motivacional pode atuar sobre o compromisso com as metas.

De acordo com Subramaniam e Mia (2001), o compromisso dos indivíduos com as metas da organização pode direcioná-los a receber tanto recompensas extrínsecas (bônus e recompensas) como recompensas intrínsecas (satisfação no trabalho e melhores relacionamentos com seus pares e superiores). Nesta pesquisa, assume-se que ambos os recursos são distintamente estimulados pela motivação individual, sob influência da participação de processos orçamentários fornecida aos indivíduos. Reconhece-se, assim, que o compromisso com as metas depende tanto do nível estrutural de participação oferecido pela organização como de diferenças individuais do subordinado (Stearns, 2016). Com base nesses argumentos, propóe-se que a participação orçamentária pode estimular o compromisso com as metas, sendo que essa relaçáo pode ser explicada pelo efeito mediador da motivação no trabalho (intrínseca e extrínseca). Assim, formula-se a terceira hipótese:

H3: A participação orçamentária, mediada pela motivaçáo no trabalho (intrínseca e extrínseca), atua positivamente sobre o compromisso com as metas orçamentárias.

Nessa hipótese, propõe-se que a participação orçamentária apresenta uma funçâo motivacional, que estimula a motivação no trabalho, tanto intrínseca como extrínseca, e que esta se reflete direta e indiretamente sobre os níveis de dedicação dos gestores com as metas orçamentárias. Na Figura 1 , representa-se o desenho desta pesquisa. 


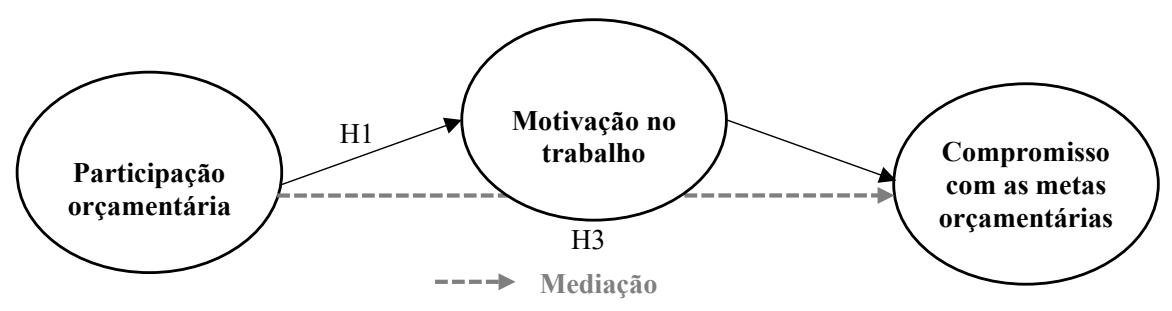

Figura 1. Modelo teórico da pesquisa.

Pelas hipóteses estabelecidas espera-se que: (a) a participação orçamentária influencie positivamente a motivação no trabalho (intrinsecamente e extrinsecamente); (b) a motivação no trabalho (intrinsecamente e extrinsecamente) influencie positivamente no compromisso com as metas orçamentárias; (c) a motivação no trabalho atue como variável mediadora entre a participação orçamentária e o compromisso com as metas.

\section{METODOLOGIA DA PESQUISA}

\section{População e amostra}

Este estudo investiga a percepção de gestores de nível intermediário (middle-level managers), de diversas áreas funcionais, conforme recomendado em estudos anteriores (Brownell \& McInnes, 1986; Chong \& Tak-Wing, 2003; Hassel \& Cunningham, 1993; Mia, 1989; Mucci, Frezatti, \& Dieng, 2016). Gestores de nível intermediário estão em posições de linha, diretamente envolvidos nas operaçóes e atividades diárias do negócio (Chong \& Tak-Wing, 2003) e se encontram um ou dois níveis abaixo da diretoria (Mucci et al., 2016), o que permite a existência de níveis distintos de participação orçamentária e compromisso com as metas.

Selecionaram-se inicialmente 195 empresas brasileiras das regióes Sul (90) e Sudeste (105) com controle acionário brasileiro, classificadas dentre as mil melhores e maiores empresas do brasil em 2016, no ranking Melhores e Maiores da Revista Exame, conforme a receita líquida anual (Revista Exame, 2017). Para os gestores que se enquadravam no perfil (atuação em nível intermediário) foi enviado o convite para comporem uma rede criada no LinkedIn, esclarecendo o intuito da pesquisa. Dentre os 1.400 convites enviados, obteve-se uma taxa de aceite de $36,3 \%$. Tomou-se o cuidado e o devido controle de envios e aceites para que ao menos três funcionários de cada empresa fossem adicionados, para fins de heterogeneidade da amostra. Depois foi encaminhado o link do questionário aos 508 gestores de nível intermediário que aceitaram o convite, sendo que 146 responderam à pesquisa.

Os dados da pesquisa foram coletados por meio de um questionário em formato QuestionPro encaminhado via LinkedIn, no período de dezembro de 2017 a março de 2018. A busca ocorreu inicialmente a partir da seleção de funcionários das 195 empresas da amostra, pelo uso dos termos "supervisor", "coordenador" e "gestor" na plataforma LinkedIn, considerando o cargo na empresa selecionada. Dentre as 195 empresas, para um número pequeno náo se conseguiu enviar o convite a nenhum gestor, e em um número razoável de empresas, mesmo após várias tentativas, ninguém aceitou o convite para o envio do link.

O tamanho da amostra necessário e o poder estatístico foram calculados com auxílio do software G*Power (Faul, Erdfelder, Buchner, \& Lang, 2009), considerando o efeito total de três variáveis preditoras (participação orçamentária, motivação intrínseca, motivação extrínseca) sobre a variável dependente (compromisso com as metas orçamentárias), ao nível de significância de 5\%, um poder estatístico de 0,95, o que indicou uma amostra mínima de 119 respostas válidas. Obteve-se um total de 146 respostas, mas 15 foram excluídas por estarem incompletas ou com respostas iguais em todas as assertivas; portanto, a amostra final foi de 131 respostas válidas.

A amostra final compõe-se de 116 homens $(88,55 \%)$ e 15 mulheres (11,45\%), com idade média de 40 anos. Cerca de $65 \%$ possuem especialização e/ou MBA, 10\% mestrado e $22 \%$ graduaçáo na área contábil, administração, gestão ou engenharia. Em relação ao cargo ocupado, 49\% atuam como gerentes, $34 \%$ como coordenadores e $17 \%$ como supervisores. Esses profissionais atuam em diferentes áreas funcionais, conforme recomendaçóes de Chong e TakWing (2003), tais como área de finanças, contábil, recursos humanos, custos, vendas e produção. Em média, possuem cinco anos de ocupaçáo do referido cargo e trabalham há aproximadamente nove anos na mesma empresa.

As empresas selecionadas possuem tamanho diferente (em média 3.300 funcionários) e atuam em segmentos distintos. Dentre 131 respondentes, foram listados 17 setores econômicos distintos, dos quais destacaram-se as participaçóes dos setores: de bens de consumo ou capital $(12,8 \%)$, serviços $(12 \%)$, energia $(11 \%)$, serviços de saúde $(9,8 \%)$, papel e celulose $(6,8 \%)$, siderurgia e metalurgia $(6 \%)$, varejo $(6 \%)$ e produção agropecuária $(5,3 \%)$. Desse modo, o estudo minimiza as limitaçóes de validade 
externa ao abranger organizaçóes bastantes distintas e áreas operacionais variadas, implicando maior possibilidade de generalização dos resultados do estudo.

\section{Mensuração das variáveis e construto da pesquisa}

Os instrumentos de mensuração dos construtos utilizaram escala tipo Likert de sete pontos (Apêndice A) e solicitaram que os respondentes indicassem para cada assertiva: a sua percepção sobre o seu nível de participação orçamentária (entre 1 = muito baixa e 7 = muito alta); a sua motivação no desempenho das tarefas do seu trabalho (entre 1 = discordo totalmente e 7 = concordo totalmente); e o grau de concordância com as assertivas em relação ao seu compromisso com as metas orçamentárias de sua organização (entre 1 = discordo totalmente e 7 = concordo totalmente). Um pré-teste foi realizado com três pesquisadores da área e três profissionais, a fim de verificar inconsistências e a interpretação de cada uma das assertivas. Revisóes na redação foram realizadas antes de disponibilizar o questionário na plataforma QuestionPro.

O construto participação orçamentária foi adaptado do instrumento de Hassel e Cunningham (1993), fundamentado por Milani (1975), e tem sido utilizado por outros pesquisadores na área (ex: Maiga, 2005). Esse instrumento compóe-se de seis assertivas e apresenta um alfa de Cronbach de 0,889. A análise fatorial exploratória (AFE) apresentou um KMO de 0,855 e uma variância total explicada (VTE) de $64,93 \%$. Já a motivação no trabalho foi baseada no estudo de Kuvaas et al. (2017) por incluir o contexto orçamentário e adotar abordagem validada na área gerencial, com os construtos de motivação em duas dimensóes (intrínseca e extrínseca) (ex: Van der Kolk et al., 2019).

Assim, a motivação foi mensurada por 10 assertivas (seis referentes à dimensão da motivação intrínseca e quatro à dimensão da motivação extrínseca). $\mathrm{Na} \mathrm{AFE}$, os construtos se agruparam em dois fatores (intrínsecos e extrínsecos), conforme apontado teoricamente, e apresentam em conjunto um KMO de 0,743 e uma VTE de 69,67\%. Para validar os construtos segundo determinação teórica, excluíram-se duas assertivas da motivação intrínseca (MINTR1; MINTR3) e uma da motivação extrínseca (MEXTR2). A motivação intrínseca indicou confiabilidade de 0,857, KMO de 0,788 e VTE de 71,83\%, já a motivação extrínseca indicou confiabilidade de 0,732, KMO de 0,686 e VTE de 65,60\%.

$\mathrm{O}$ construto compromisso com as metas orçamentárias foi mensurado pelo instrumento de referência à área orçamentária, proposto por Chong e Chong (2002), composto de quatro assertivas, sendo CMO4 reversa. $\mathrm{Na}$ AFE foi excluída uma assertiva (CMO4). Após a exclusão, esse construto apresentou um alfa de Cronbach de 0,692, KMO de 0,667 e VTE de 63,72\%. Variáveis de controle (sexo, idade, escolaridade, cargo, área de atuaçáo, tempo de empresa, tempo no cargo e setor) foram adicionadas ao modelo para verificar a correlaçáo com os demais construtos e seus efeitos sobre a variável dependente. Embora algumas dessas variáveis tenham apresentado correlaçóes significativas com os construtos no modelo de mensuração, sua inclusão no modelo estrutural não influenciou os resultados e coeficientes de caminho.

\section{Procedimentos de análise dos dados}

Foram realizados testes de viés de não resposta para validar as informaçóes obtidas pelos instrumentos de pesquisa. Primeiro adotou-se o método first last (comparação das médias das 10 primeiras com as 10 últimas respostas) e não houve diferenças estatisticamente significativas em nenhum dos construtos (p-values entre 0,1204 e 0,609$)$. O mesmo ocorreu ao analisar a média das respostas iniciais com as finais ( $p$-values entre 0,253 e 0,592). Posteriormente, realizaram-se testes de confiabilidade e AFE, com análise do viés de método comum (common bias method), pelo teste de fator único de Harman. A variância total explicada para um único fator foi $68,03 \%$, que descarta a tendência de método comum e sugere que os instrumentos não introduziram variaçóes nas respostas, nem ruídos nos dados e em suas inferências teóricas e estatísticas (Podsakoff, MacKenzie, Lee, \& Podsakoff, 2003).

Para análise dos dados, contou-se com o auxílio do SPSS para a análise exploratória e descritiva dos dados e do Smarth-PLS para a modelagem de equaçóes estruturais (SEM). Essa técnica é utilizada para analisar os dados e testar as hipóteses, estimados a partir dos mínimos quadrados parciais (partial least squares - PLS). Possibilita estimar uma série de equações de regressão múltiplas separadas, mas interdependentes, de forma simultânea, pela especificação do modelo estrutural (Hair, Hult, Ringle, \& Sarstedt, 2014).

A modelagem de equações estruturais objetiva examinar a estrutura nas inter-relaçóes entre os construtos da análise, que combina o uso dos métodos multivariados de análise fatorial e de análise de regressão múltipla (Hair, Anderson, Tatham, \& Black, 2009). O uso do Smarth-PLS na SEM tem por base um conjunto de critérios de avaliação não paramétricos, empregando procedimentos como bootstrapping e blindfolding para a avaliação do modelo de mensuração das medidas dos construtos (validade convergente e discriminante e confiabilidade interna e composta) e do modelo estrutural (tamanho e significância dos coeficientes de caminho [path], validade preditiva do 
modelo $\left[\mathrm{R}^{2}\right]$, relevância preditiva $\left[\mathrm{Q}^{2}\right]$ e tamanhos do efeito $\left[\mathrm{F}^{2}\right]$ ) (Hair et al., 2014).

$\mathrm{Na}$ análise, também se realizaram testes de mediação, considerando que a mediaçáo pode ser entendida como um mecanismo pelo qual a variável independente influencia a variável dependente, por meio da transmissão de efeitos da variável mediadora (Baron \& Kenny, 1986). Hayes (2013) destaca que a variável mediadora atua na demonstração de evidências ou teste de hipóteses sobre procedimentos que explicam a ocorrência de certos efeitos, ou ainda em que condiçôes atuam como facilitadores ou inibidores de tais efeitos. Além de seguir as recomendaçôes de Baron e Kenny (1986), as mediaçóes foram confirmadas pelas análises no bootstrapping, com 5.000 interaçôes (SmartPLS), o que auxilia para testar as hipóteses de mediação por meio de um teste rigoroso dos efeitos indiretos, avaliando e comparando os efeitos indiretos em modelos de mediadores (Hayes, 2013).

\section{ANÁLISE DOS RESULTADOS}

\section{Modelo de mensuração}

O modelo de mensuração demonstrou que todos os construtos possuem variância média extraída (average variance extracted - AVE) superior a 0,5 (Hair et al., 2009). Os testes de confiabilidade (interna e composta) também atestaram que as respostas da amostra são confiáveis e náo contêm vieses - todos os construtos apresentaram-se superiores a 0,70 (Hair et al., 2014). Para testar a validade discriminante, foram avaliados os critérios de Chin (1998) das cargas cruzadas (cross loading, Apêndice A) e o critério recomendado por Fornell e Larcker (1981) (Tabela 1). Em ambos os testes, verificou-se a força de cada construto em se diferenciar dos demais e captar fenômenos exclusivos no modelo proposto. A raiz quadrada de cada AVE (diagonal, Tabela 1) apresenta maior explicação em seu próprio construto do que os valores referentes às correlaçóes entre os demais construtos, com valores superiores a 0,7 .

Tabela 1. Validade do modelo de mensuração.

\begin{tabular}{|c|c|c|c|c|c|c|c|c|c|c|c|c|}
\hline Descrição & 1 & 2 & 3 & 4 & 5 & 6 & 7 & 8 & 9 & 10 & 11 & 12 \\
\hline 1 Participação orçamentária & 0,805 & & & & & & & & & & & \\
\hline 2 Motivação intrínseca & 0,470 & 0,847 & & & & & & & & & & \\
\hline 3 Motivação extrínseca & $-0,191$ & $-0,049$ & 0,799 & & & & & & & & & \\
\hline 4 Compromisso com metas & 0,436 & 0,460 & $-0,178$ & 0,798 & & & & & & & & \\
\hline 5 Idade & 0,111 & 0,217 & $-0,233$ & 0,111 & 1 & & & & & & & \\
\hline 6 Gênero & 0,021 & $-0,049$ & $-0,002$ & 0,079 & 0,143 & 1 & & & & & & \\
\hline 7 Escolaridade & 0,089 & 0,161 & $-0,153$ & 0,153 & 0,132 & $-0,048$ & 1 & & & & & \\
\hline 8 Cargo & 0,328 & 0,188 & 0,127 & 0,138 & 0,257 & 0,123 & 0,260 & 1 & & & & \\
\hline 9 Tempo no cargo & 0,110 & 0,047 & 0,042 & 0,050 & 0,428 & 0,166 & 0,101 & $-0,139$ & 1 & & & \\
\hline 10 Tempo na empresa & 0,173 & 0,202 & 0,094 & 0,110 & 0,285 & 0,087 & $-0,102$ & 0,044 & 0,562 & 1 & & \\
\hline 11 Área & 0,168 & 0,081 & $-0,076$ & $-0,010$ & $-0,049$ & 0,119 & 0,114 & $-0,083$ & 0,065 & 0,118 & 1 & \\
\hline 12 Setor & 0,084 & 0,031 & $-0,010$ & $-0,045$ & $-0,119$ & $-0,165$ & 0,070 & $-0,070$ & $-0,109$ & $-0,105$ & 0,131 & 1 \\
\hline
\end{tabular}

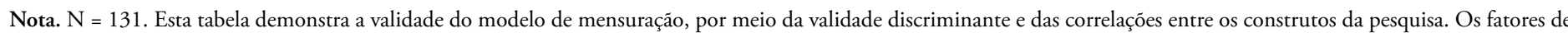

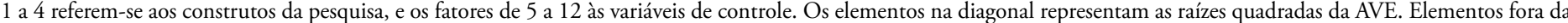

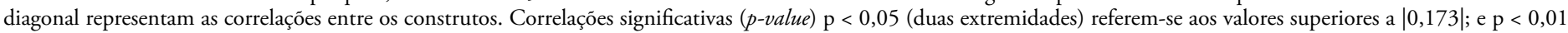
(duas extremidades) referem-se aos valores superiores a $|0,233|$.

Observa-se que a participação orçamentária interage positivamente com a motivação intrínseca $(\beta 0,470, p<0,01)$ e com o compromisso com as metas orçamentárias $(\beta 0,436$, $\mathrm{p}<0,01)$, e negativamente com a motivação intrínseca $(\beta-0,191, p<0,05)$. Da mesma forma, compromisso com as metas orçamentárias interage positivamente com motivação intrínseca $(\beta 0,460, \mathrm{p}<0,01)$ e negativamente com motivação extrínseca $(\beta-0,178, \mathrm{p}<0,05)$. Isso sugere que a participação pode ser um antecedente que estimula psicologicamente os indivíduos, mas pode não influenciar ou até mesmo desestimular atitudes que priorizem resultados e/ou benefícios financeiros. Além disso, acredita-se que um maior compromisso com os resultados possa ser decorrente de maior estímulo intrínseco do que extrínseco, ao passo que este último pode desvirtuar o foco dos seus objetivos e do seu efetivo alcance. 
Algumas variáveis de controle apresentaram correlaçôes significativas, tais como: (a) idade do gestor, que se correlaciona positivamente com motivação intrínseca $(0,217, \mathrm{p}<0,05)$ e negativamente com motivação extrínseca $(-0,233, \mathrm{p}<0,01)$, o que pode sinalizar que indivíduos mais velhos possuem maior necessidade de motivação intrínseca e menor necessidade de motivação extrínseca (remuneração, retornos sobre desempenho); (b) nível de cargo do gestor, com a participação orçamentária $(0,328, \mathrm{p}<0,01)$ e a motivação intrínseca $(0,188, \mathrm{p}<0,05)$, o que pode indicar que cargos mais elevados, como gerentes de área, possuem maior participação orçamentária e maiores níveis de motivação intrínseca no exercício de suas funçóes; e (c) tempo de empresa dos gestores com seu nível de participação orçamentária $(0,173, \mathrm{p}<0,05)$ e motivação intrínseca $(0,202, p<0,05)$, fatores que podem sugerir que um maior tempo de empresa pode induzir a um maior envolvimento com os orçamentos e a sentimentos intrínsecos.

As medidas de variance inflation factor (VIF), que avaliam a existência de colinearidade entre as variáveis, revelaram que todos os indicadores se apresentam inferiores a cinco, sendo que o VIF externo variou entre $1,373 \mathrm{e}$ 3,588 , e o VIF interno entre 1 e 1,332. O modelo fit, que indica o ajustamento do modelo, apresentou um SRMR (raiz quadrada média residual padronizada) de 0,076, um qui-quadrado de 274,529 e um NFI de 0,751 , o que sugere que a estrutura hipotética do modelo se ajusta aos dados empíricos. Dessa maneira, seguindo-se os pressupostos sugeridos por Hair et al. (2009), e constatada a presença de associações entre as variáveis, validam-se os construtos e atesta-se a validade do modelo de mensuração. Assim, seguese com a avaliação do modelo estrutural.

\section{Modelo estrutural}

A análise do modelo estrutural busca verificar a validade estatística e confirmar a adequação do modelo de mensuração, atestando a significância das relaçóes entre os construtos do estudo e a confirmação das hipóteses. Na Tabela 2 constam os resultados dos testes path, t-value, p-value $\mathrm{F}^{2}$ e $\mathrm{R}^{2}$.

Tabela 2. Análise do modelo estrutural.

\begin{tabular}{|c|c|c|c|c|c|c|}
\hline Hipóteses & Path & Coef. & DP & T-value & $\mathrm{F}^{2}$ & $\mathrm{R}^{2}$ \\
\hline $\mathrm{H}_{1 \mathrm{a}}$ & Participação orçamentária $\rightarrow$ Motivação intrínseca & 0,470 & 0,088 & $5,342^{* * *}$ & 0,284 & 0,221 \\
\hline $\mathrm{H}_{1 \mathrm{~b}}$ & Participação orçamentária $\rightarrow$ Motivação extrínseca & $-0,191$ & 0,099 & $1,934^{*}$ & 0,038 & 0,037 \\
\hline $\mathrm{H}_{2 \mathrm{a}}$ & Motivação intrínseca $\rightarrow$ Compromisso com as metas & 0,333 & 0,079 & $4,214^{* * *}$ & 0,121 & \multirow{4}{*}{0,285} \\
\hline $\mathrm{H}_{2 \mathrm{~b}}$ & Motivação extrínseca $\rightarrow$ Compromisso com as metas & $-0,112$ & 0,101 & 1,113 & 0,017 & \\
\hline $\mathrm{H}_{3 \mathrm{a}}$ & $\begin{array}{l}\text { Participaçáo orçamentária } \rightarrow \text { Motivação intrínseca } \\
\rightarrow \text { Compromisso com as metas }\end{array}$ & 0,157 & 0,044 & $3,571^{* * *}$ & \multirow{2}{*}{0,070} & \\
\hline $\mathrm{H}_{3 \mathrm{~b}}$ & $\begin{array}{l}\text { Participação orçamentária } \rightarrow \text { Motivação extrínseca } \\
\rightarrow \text { Compromisso com as metas }\end{array}$ & 0,021 & 0,025 & 0,874 & & \\
\hline
\end{tabular}

Nota. $\mathrm{N}=131$. Esta tabela demonstra a análise do modelo estrutural (path, $t$-value, p-value $\mathrm{F}^{2}$ e $\mathrm{R}^{2}$ ) para as relaçóes propostas nesta pesquisa e respectivas hipóteses. Os testes foram realizados via bootstrapping, por meio de testes bicaudais, significância de $95 \%$ (bias-corrected and accelerated), com 5.000 interaçōes. Relaçóes significativas ( $p$-value) ${ }^{*} \mathrm{p}<0,05 ;{ }^{* *} \mathrm{p}<0,01 ;{ }^{* * *} \mathrm{p}<0,000$.

Observa-se na Tabela 2 que a hipótese $\mathrm{H}_{1 \mathrm{a}}$, que previa relação entre participação orçamentária e motivação intrínseca $(\beta 0,470, \mathrm{p}<0,000)$, pode ser aceita, assim como a $\mathrm{H}_{1 b}$, que previa associação entre participação orçamentária e motivaçáo extrínseca $(\beta-0,191, p<0,05)$, mas essa relaçáo é negativa. Esses resultados estáo alinhados com discussóes anteriores, quanto à associação da participação orçamentária com efeitos motivacionais (Birnberg et al., 2007). Argumenta-se que a participação dos indivíduos no planejamento orçamentário motiva-os a atuarem por si próprios para o alcance das metas e que, quanto maiores as possibilidades de se envolverem no orçamento, menores serão suas buscas por motivaçóes extrínsecas (bonificações, prêmios, recompensas).
A motivação intrínseca apresentou relação positiva e significativa com o compromisso com as metas orçamentárias $(\beta 0,333, \mathrm{p}<0,000)$, o que permite confirmar a $\mathrm{H}_{2 \mathrm{a}}$. Esse resultado reforça que maior envolvimento dos indivíduos pode estar atrelado a efeitos positivos nos resultados organizacionais (Pinder, 2011). Já a hipótese $\mathrm{H}_{2 b}$, que previa associaçáa entre motivaçáo extrínseca e compromisso com as metas orçamentárias, apresenta relação negativa e não significativa $(\beta-0,112)$ entre as variáveis. Isso sugere que estímulos remuneratórios não são suficientes para assegurar compromisso com as metas orçamentárias.

Embora as variáveis de controle idade, nível de cargo do gerente e tempo de empresa tenham apresentado correlaçóes significativas com os construtos (Tabela 1), ao 
incluí-las no modelo estrutural não se observaram influências significativas $(\mathrm{p}>0,10)$ sobre a variável dependente. Em função disso, elas não são representadas nesta análise nem incluídas na Tabela 2.

Relação positiva e significativa foi confirmada entre participaçáo orçamentária e compromisso com as metas orçamentárias $(\beta 0,436, \mathrm{p}<0,000)$. Esse resultado, tal como evidenciado em estudos anteriores (Chong \& Chong, 2002; Lavarda et al., 2015; Shields \& Shields, 1998; Sholihin et al., 2011), indica que indivíduos, ao terem a oportunidade de se envolver e influenciar no processo de escolhas, são mais estimulados a atingir as metas, por se sentirem responsáveis pelos resultados alcançados. Esse efeito direto significativo entre as variáveis independentes (VI - Participação orçamentária) e dependentes (VD - Compromisso com as metas orçamentárias) permite realizar os testes de mediação (Baron \& Kenny, 1986).

Com a inclusão das variáveis mediadoras, tem-se um total de efeitos indiretos de $0,178(\mathrm{p}<0,000)$, o que sugere que a motivação no trabalho consegue ajudar a explicar melhor a interação entre essas variáveis (Hayes, 2013). Além disso, o efeito total (c') é reduzido $(\beta 0,257, \mathrm{p}<0,01)$ com a inclusão dessas variáveis, conforme ilustra a Figura 2. Isso permite afirmar que a motivação no trabalho medeia parcialmente as interaçóes entre a participação orçamentária e o compromisso com as metas orçamentárias. Em específico, o resultado revela que a motivação intrínseca exerce um papel praticamente exclusivo nessas interaçóes $(\beta 0,157, \mathrm{p}<0,000)$, já que a motivação extrínseca parece não ser capaz de atuar como interveniente entre essas duas variáveis. Com isso, confirma-se parcialmente $\mathrm{H}_{3 \mathrm{a}}$.

$\mathrm{O} \mathrm{F}^{2}$ extraído via bootstrapping das interaçóes entre os construtos revela que a participação orçamentária e a motivação intrínseca possuem um tamanho de efeito médio (entre 0,15 e 0,35 ) sobre a variável dependente (Hair et al., 2014). As demais interações possuem um efeito pequeno (entre 0,02 e 0,15 ). Os testes de $\mathrm{F}^{2}$ na plataforma blindfolding mostram que a motivação intrínseca $(0,14)$ apresenta um tamanho de efeito pequeno, o compromisso com as metas $(0,15)$ um efeito médio e a motivaçáo extrínseca não pontuou.

O teste $\mathrm{Q}^{2}$ avalia o quanto o modelo se aproxima do que se esperava dele na predição do modelo. Os valores devem ser maiores que zero e um modelo perfeito teria um $\mathrm{Q}^{2}=1$ (Hair et al., 2014). Encontraram-se os seguintes valores para cada um dos construtos: participação orçamentária 0,479 , motivação intrínseca 0,502 , motivação extrínseca 0,281 e compromisso com as metas orçamentárias 0,281 . Isso indica que existe conformidade no modelo ajustado. Na Figura 2 apresenta-se uma síntese dos principais efeitos evidenciados pelos coeficientes de caminhos, significância e $\mathrm{R}^{2}$.

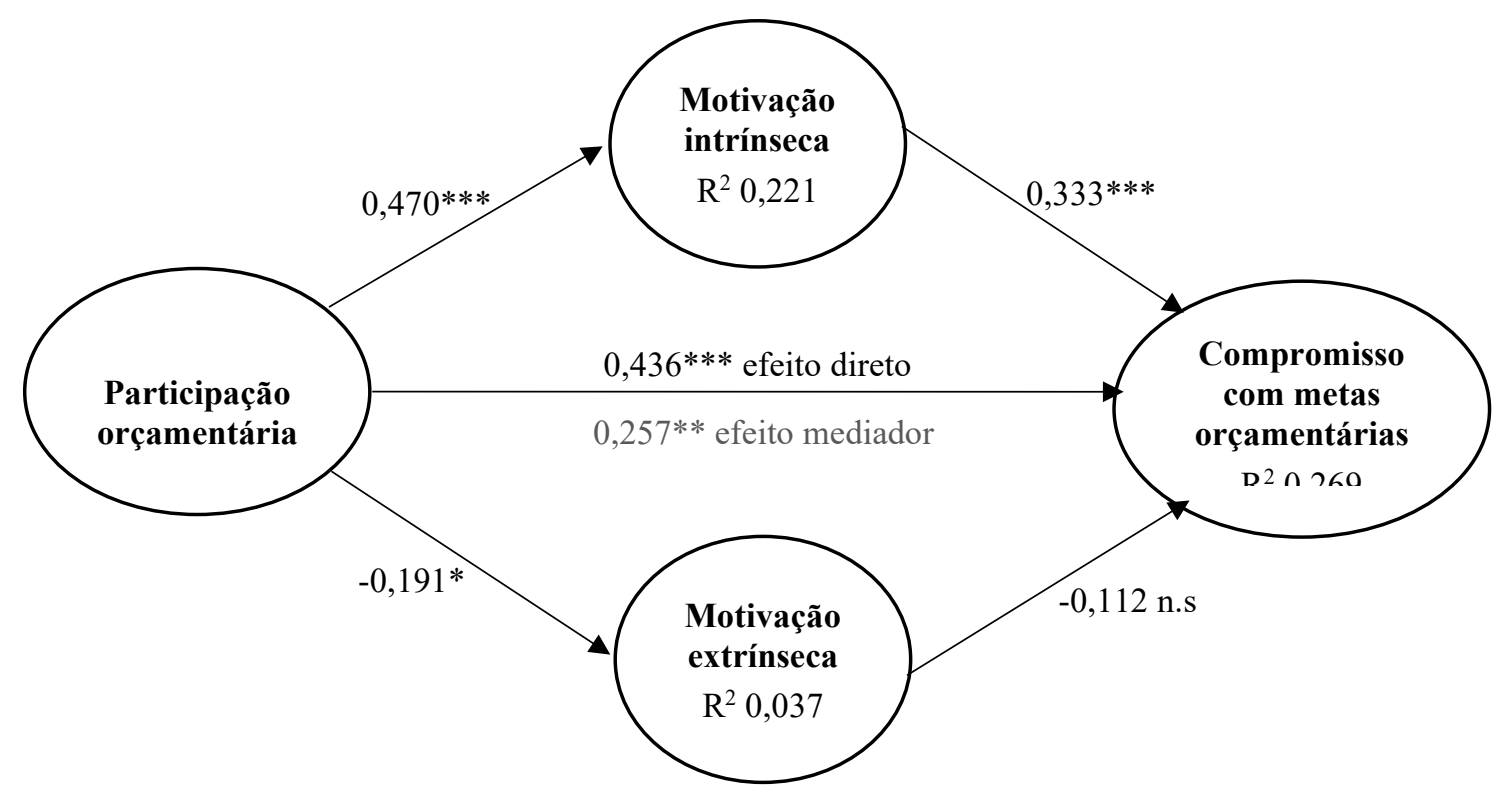

Figura 2. Modelo estrutural e suas interaçôes.

$\mathrm{N}=131$. Significativo ( $p$-value) ao nível de ${ }^{*} \mathrm{p}<0,05$; $^{* *} \mathrm{p}<0,01{ }^{* * *} \mathrm{p}<0,000$. O efeito mediador é decorrente do efeito c' de VI $\rightarrow \mathrm{VD}$ sob influência da variável mediadora (motivação no trabalho), as demais interaçôes (path) correspondem a relaçóes diretas. 
Conforme Figura 2 e Tabela 2, a motivação extrínseca apresentou um coeficiente de determinação de Pearson $\left(\mathrm{R}^{2}\right)$ baixo $(3,7 \%)$, a motivação intrínseca um $\mathrm{R}^{2}$ médio (22\%) e o compromisso com as metas orçamentárias um efeito grande (27\%) (Cohen, 1988). Infere-se, assim, que apenas a motivação extrínseca não pode ser considerada o melhor preditor para explicar interaçóes entre as variáveis. Já a motivação intrínseca, além de evidenciar relações diretas positivas e significativas com a participação orçamentária e compromisso com as metas orçamentárias, também atua como variável mediadora (efeitos indiretos) entre essas duas variáveis, pois sua inclusão no modelo reduz o efeito direto entre as variáveis, como demonstra a Figura 2 (sem mediação $\beta 0,436, \mathrm{p}<0,000$; com mediaçáo $\beta 0,257, \mathrm{p}<0,01$ ).

\section{Discussão dos resultados}

Os resultados desta pesquisa revelam que ao propiciarem maior envolvimento dos gestores na definiçáo de seus orçamentos e que possam fornecer e receber informaçóes relativas ao processo orçamentário, as organizações auferem consequências positivas no desempenho individual e gerencial, tanto de ordem psicológica, pelo estímulo motivacional (principalmente intrínseco), quanto de ordem comportamental, pelo maior comprometimento com as metas orçamentárias. De modo geral, a participação orçamentária, ao possibilitar a expressão e ampliar a comunicação (opiniōes, sugestôes, previsóes) entre os diferentes níveis organizacionais, além das contribuiçóes ao processo de elaboração do orçamento, influenciará sua execução, de forma que haverá maior esforço em prol do alcance das metas.

Confirmaram-se as relaçóes entre participação orçamentária e motivaçáa intrínseca $\left(\mathrm{H}_{1 \mathrm{a}}\right)$. Essa evidência corrobora Baerdemaeker e Bruggeman (2015) e Djalil, Indriani e Muttaqin (2017) e indica que a oportunidade de os indivíduos serem ouvidos pelo conhecimento e/ou experiência adquiridos em suas atividades permite conectálos ao processo em si e não a resultados (Vallerand, 1997). A participação orçamentária parece favorecer sentimentos de realizaçáo, senso de satisfação pessoal, sentimento de pertencimento e maior identificação organizacional (Wong-On-Wing et al., 2010). Consoante a teoria da autodeterminação, a participação orçamentária fornece um ambiente de suporte às necessidades psicológicas básicas dos indivíduos, e propicia maior motivação intrínseca (Van der Kolk et al., 2019).

Os resultados entre participação orçamentária e motivação extrínseca $\left(\mathrm{H}_{1 \mathrm{~b}}\right)$ apontaram relações negativas e significativas. Isso indica que, ao aumentar o nível de participação orçamentária, reduz-se o nível de necessidade de motivaçóes extrínsecas para a realização no trabalho. Groen, Wouters e Wilderom (2017) observaram que aqueles funcionários que possuem tarefas interessantes podem expressar motivação autônoma (inclui a motivação intrínseca) para realizar as tarefas que deles são esperadas. Isso dispensaria a existência de estímulos decorrentes de incentivos externos para o desempenho, já que as pessoas podem se sentir menos autônomas ao perceberem os incentivos como elementos que atuam como opressores e controladores (ex.: recompensas monetárias). Portanto, o envolvimento e a participação no processo orçamentário proporcionam ao indivíduo maior autonomia e autodeterminação e, com isso, aspectos voltados à motivaçáo extrínseca seriam reduzidos, tal como as expectativas de recursos favoráveis inerentes às atividades (Ryan \& Deci, 2000).

A motivação intrínseca no trabalho revelou-se significativa ao explicar interaçóes com o compromisso com as metas $\left(\mathrm{H}_{2 \mathrm{a}}\right)$. Especula-se que o fator motivacional intrínseco possa atuar de forma mais incisiva no compromisso com as metas, porque a obtenção de realizaçóes e satisfação individuais decorre do atingimento de um objetivo (WongOn-Wing et al., 2010), sendo que alcançar uma meta pode atuar como uma recompensa psicológica desfrutada pelo indivíduo, independentemente do salário (GómezMiñambres, 2012).

As evidências não confirmaram que a motivação extrínseca dos gerentes é fator suficiente para aumentar o compromisso com as metas $\left(\mathrm{H}_{2 \mathrm{~b}}\right)$, tal como ocorreu no estudo de Lavarda, Sant'Ana, Manfroi e Dagostini (2015), em que os funcionários cientes que iriam receber uma participação monetária (medida de motivação extrínseca) tinham maior aceitação e compromisso com as metas. Essa evidência pode sinalizar que os gestores intermediários, em decorrência de seus cargos, idade e tempo de empresa (variáveis correlacionadas significativamente com a motivaçáo intrínseca), podem ser mais atraídos ou propensos a estímulos/recompensas intrínsecas do que a estímulos/recompensas extrínsecas, como poder-se-ia supor (Van der Kolk et al., 2019). É importante ressaltar que essas evidências podem ser particulares da amostra pesquisada e que, portanto, merecem mais investigaçôes.

A relação entre participação orçamentária e compromisso com as metas orçamentárias, além de significativa e de corroborar a literatura anterior (Lavarda et al., 2015; Macinati \& Rizzo, 2014), confirma também ser influenciada indiretamente (por meio de mediação) pela motivaçáo no trabalho $\left(\mathrm{H}_{3}\right)$. Corrobora-se que a participação orçamentária pode desencadear efeito motivacional (Maiga, 2005) e repercutir positivamente nos esforços com as metas orçamentárias (Lavarda et al., 2015). Isso indica que funcionários podem sentir maior vínculo emocional com a organizaçáa quando há valorização de sua participação orçamentária e se sentirão motivados intrinsecamente para atingir as metas de desempenho 
esperadas pela organização (Allen \& Meyer, 1993). Conforme a teoria da autodeterminação, ao permitirlhes ter contato com informaçóes relativas à elaboração orçamentária e possibilitar-lhes atuar na comunicação/ discussão e expressar opinióes, tal poderá se refletir sobre decisóes que afetarão o desempenho da organização. Da mesma forma, as necessidades de relacionamento podem ser satisfeitas pela interação social que ocorre durante o processo de participação orçamentária, proporcionando maior motivação intrínseca e, consequentemente, refletindo-se no desempenho no trabalho do funcionário (Deci et al., 1989).

No entanto, esse efeito motivacional refere-se apenas à motivação intrínseca, visto que a motivação extrínseca não demonstrou influência significativa na relação direta entre a participação e o compromisso com metas orçamentárias. Isso permite aceitar parcialmente $\mathrm{a}_{3}$. Esses resultados sugerem que a participaçáo orçamentária pode ser considerada uma variável mais complexa do que se pensava anteriormente (Stearns, 2016). Ela pode, além de se refletir em maiores comportamentos positivos, como compromisso com metas orçamentárias (Maiga, 2005), ser capaz de estimular mais efetivamente a motivação intrínseca dos funcionários. Ao permitir discussóes e envolvimento no orçamento, geram-se sentimentos de influência e contribuiçôes no orçamento e metas finais (Milani, 1975), que podem levar ao aumento do compromisso afetivo dos gestores (efeito motivacional intrínseco).

De forma geral, os resultados da pesquisa revelam que o aumento da participação orçamentária percebida pelos funcionários resultará em aumentos motivacionais para atingir as metas orçamentárias, por envolver os indivíduos, que exibem níveis mais elevados de motivação (intrínseca) e que, consequentemente, tenderão a contribuir positivamente para o aumento do desempenho individual e da empresa (Stearns, 2016). Por sua vez, a busca por retornos extrínsecos pode ficar em segundo plano ao se deparar com as mobilizaçôes psicológicas decorrentes da participação orçamentária.

As evidências desta pesquisa corroboram as de Isgiyarta, Nugrobo, Ratmono, Helmina e Pamungkas (2019). Os autores ressaltam que a participação no orçamento é um meio de aferir o cumprimento das metas organizacionais de cada gerente, e um maior envolvimento do funcionário no processo de preparaçáo do orçamento irá encorajar a sua motivação para completar com sucesso a tarefa, obter prêmios, ter responsabilidade pelo trabalho e evitar insatisfação no trabalho (elementos intrínsecos). Reconhece-se que a motivação intrínseca é difícil de ser ativada (Van der Kolk et al., 2019), que o compromisso com as metas representa um resultado desejável (Welsh et al., 2020), e que a participação orçamentária configura uma variável antecedente importante na abordagem do processo cognitivo relacionado ao desempenho do funcionário e gerencial.

\section{Implicações do estudo}

As evidências desta pesquisa contribuem para as discussões sobre as implicaçôes do aumento da participação orçamentária no desempenho de gestores. Revelam que a participação e o envolvimento dos funcionários no desenvolvimento de métricas de desempenho (metas orçamentárias) são importantes para melhorar a qualidade destas (Groen, Wouters, \& Wilderom, 2017), por meio de comportamentos que denotam maior comprometimento com as metas. Ademais, estímulos aos efeitos motivacionais intrínsecos consequentes do processo orçamentário reforçam efeitos psicológicos e cognitivos dos funcionários que irão se envolver, comunicar e expressar suas opinióes sobre o processo orçamentário.

Empiricamente se demonstrou que o compromisso com as metas orçamentárias, além de ser diretamente influenciado pela motivação intrínseca individual (o desejo de escolher fazer pelo prazer que isso lhe oferece) e pela possibilidade de o indivíduo participar do processo orçamentário, pode ser explicado indiretamente por fatores motivacionais. Esse achado reforça as argumentaçóes de que a participação do indivíduo no processo orçamentário pode levar a um compromisso afetivo com o objetivo (Meyer et al., 2004), seja em melhor aceitar o compromisso com o orçamento (Shields \& Shields, 1998), seja em auxiliar na definiçâao de metas mais altas e aumentar o desempenho (Locke \& Latham, 2002). Pode ainda reforçar uma menor busca por fatores extrínsecos (Groen et al., 2017), na medida em que sentem suas necessidades psicológicas básicas atendidas, fomentando os aspectos intrínsecos.

Assim, os achados desta pesquisa corroboram os argumentos da teoria da determinação das metas, referida por Locke e Latham (1990), de que a participação orçamentária dos indivíduos pode aumentar o compromisso com as metas. Além disso, corroboram os argumentos associados à teoria da autodeterminação de Ryan e Deci (2000), ao atestar que as motivações individuais são construtos multidimensionais orientados e determinados por contextos que substanciam suas necessidades psicológicas com diferentes manifestaçōes.

Do ponto de vista prático, este estudo presume que as empresas precisam garantir que os gestores participem e se envolvam nos processos orçamentários para obter desempenhos individuais mais positivos no trabalho. Os superiores precisam entender os benefícios que podem auferir ao propiciar oportunidades de ampliaçáo da participaçáo orçamentária de seus subordinados, reconhecendo tanto as suas influências diretas como as indiretas, que incluem 
o âmbito comportamental (compromisso) e motivacional (especialmente intrínseco).

\section{CONSIDERAÇÕES FINAIS}

Este estudo analisou as interações entre a participação orçamentária, a motivação no trabalho (intrínseca e extrínseca) e o compromisso com as metas orçamentárias. Os resultados indicaram que tanto a participação orçamentária como o compromisso com as metas orçamentárias são associados positivamente à motivaçáo intrínseca e negativamente à motivação extrínseca. A participação orçamentária, além de afetar diretamente o compromisso com as metas orçamentárias, tem essa interaçáo mediada pela motivação intrínseca. Isso sugere que conceder aos gestores intermediários maior participação e envolvimento no processo orçamentário gera sentimentos positivos, como maior motivação intrínseca e identificação com as metas orçamentárias. A participação orçamentária também parece ser capaz de reduzir a busca por motivação extrínseca, mas não influencia diretamente no compromisso com as metas orçamentárias, o que merece mais investigaçóes.

Por se tratar de uma pesquisa de natureza transversal, cabem ressalvas quanto à capacidade de generalização dos resultados, já que focou apenas em gerentes de níveis intermediários. Com isso, a pesquisa pode estar sujeita a limitaçóes de viés de método comum, autoavaliação e taxas das respostas dos participantes e efeito halo, embora tenham sido realizados testes para verificar a tendência desses elementos e os resultados não terem indicado tendência de método comum. Além disso, as respostas validaram as informaçóes

\section{REFERÊNCIAS}

Allen, N. J. \& Meyer, J. P. (1993). Organizational commitment: Evidence of career stage effects? Journal of Business Research, 26(1), 49-61. https://doi.org/10.1016/0148-2963(93)90042-N

Almasi, H., Palizdar, M. R., \& Parsian, H. (2015). Budgetary participation and managerial performance: The impact of information and environmental volatility. Management Science Letters, 5(9), 843-854. https://doi.org/10.5267/j.msl.2015.7.001

Argyris, C. (1952). The impact of budgets on people. In R. Ashton (Ed.), The evolution of behavioral accounting research (RLE accounting). New York: Controllership Foundation.

Badu, I, Awaluddin, I., \& Mas'ud, A. (2019). Pengaruh partisipasi penyusunan anggaran, komitmen organisasi, profesionalisme, gaya kepemimpinan dan struktur organisasi terhadap kinerja managerial. Jurnal Progres Ekonomi Pembangunan, 4(1), 99-113. Retrieved from http://ojs.uho.ac.id/index.php/JPEP/article/view/6247 obtidas nos instrumentos de pesquisa pelos testes de viés de não resposta. Ademais, outros cuidados metodológicos, como o uso de instrumentos que possibilitam a mensuração em escalas multidimensionais diferentes (instrumentos diferentes), tornam as autoavaliaçóes menos suscetíveis ao efeito halo. Os testes de confiabilidade e multicolinearidade também indicaram que as respostas podem ser consideradas consistentes e adequadas para inferências teóricas e estatísticas, já que os construtos apresentaram validade interna e externa.

Este estudo limitou-se a investigar antecedentes do compromisso com as metas orçamentárias sob a ótica dos indivíduos envolvidos nesse processo, portanto, estudos futuros poderiam investigar antecedentes da participaçáo orçamentária (Shields \& Shields, 1998). Da mesma forma, os consequentes do compromisso com as metas poderiam ser explorados em pesquisas futuras, como, por exemplo, o desempenho de tarefas e o desempenho gerencial. A inclusão de outros elementos (antecedentes e consequentes) pode contribuir para melhor compreender as interaçóes entre as motivaçóes, principalmente a motivaçáo extrínseca. Embora sejam sugeridas associaçóes do compromisso com as metas, não se encontrou suporte para essas relaçóes. Estudos futuros podem explorar efeitos psicológicos (atenção, esforço e persistência) relacionados à dificuldade atrelada à meta. Esses estudos podem tanto analisar as relaçóes de causalidade quanto as relaçóes de bidirecionalidade (Nouri \& Kyj, 2008). Por fim, pesquisas futuras podem investigar possíveis comportamentos disfuncionais (efeito negativo) atrelados ao controle orçamentário, como, por exemplo, criação de folga orçamentária e superestimação de custos e vendas no processo de preparação dos orçamentos.
Baerdemaeker, J. D., \& Bruggeman, W. (2015). The impact of participation in strategic planning on managers' creation of budgetary slack: The mediating role of autonomous motivation and affective organizational commitment. Management Accounting Research, 29(1), 1-12. http://doi.org/10.1016/j.mar.2015.06.002

Baron, R. M., \& Kenny, D. A. (1986). The moderator-mediator variable distinction in social psychological research: Conceptual, strategic, and statistical considerations. Journal of Personality and Social Psychology, 51(6), 11731182. https://doi.org/10.1037//0022-3514.51.6.1173

Birnberg, J. G., Luft, J., \& Shields, M. D. (2007). Psychology theory in management accounting research. In C. S. Chapman, A. G. Hopwood, M. D. Shields (Eds.), Handbook of management accounting research (Chap. 1.03). Amsterdam: Elsevier. 
Brownell, P., \& McInnes, M. (1986). Budgetary participation, motivation, and managerial performance. The Accounting Review, 61(4), 587-600. Retrieved from https://www.jstor.org/stable/247359

Chin, W. W. (1998). The partial least squares approach for structural equation modeling. In G. A. Marcoulides (Ed.), Methodology for business and management: Modern methods for business research (pp. 295-336). Hillsdale, NJ: Lawrence Erlbaum Associates.

Chong, V. K., \& Chong, K. M. (2002). Budget goal commitment and informational effects of budget participation on performance: A structural equation modeling approach. Behavioral Research in Accounting, 14(1), 65-86. https://doi.org/10.2308/bria.2002.14.1.65

Chong, V. K., Eggleton, I., \& Leong, M. (2005). The impact of market competition and budgetary participation on performance and job satisfaction: A research note. The British Accounting Review, 37(1), 115-133. https://doi.org/10.1016/j.bar.2004.06.007

Chong, V. K, \& Johnson, D. M. (2007). Testing a model of the antecedents and consequences of budgetary participation on job performance. Accounting and Business Research, 37(1), 3-19. https://doi.org/10.1080/00014788.2007.9730055

Chong, V. K., \& Tak-Wing, S. L. (2003). Testing a model of the motivational role of budgetary participation on job performance: A goal setting theory analysis. Asian Review of Accounting, 11(1), 1-17. https://doi.org/10.1108/eb060760

Cohen, J. (1988). Statistical power analysis for the behavioral sciences (2 ed.). Hillsdale, NJ: Lawrence Erlbaum Associates.

Covaleski, M., Evans III, J. H., Luft, J., \& Shields, M. D. (2007). Budgeting research: Three theoretical perspectives and criteria for selective integration. In C. S. Chapman, A. G. Hopwood, M. D. Shields (Eds.), Handbook of management accounting research (Chap. 6, pp. 587-624). Amsterdam: Elsevier.

Dani, A. C., Zonatto, V. C. S., \& Diehl, C. A. (2017). Participação orçamentária e desempenho gerencial: Uma meta-análise das relaçóes encontradas em pesquisas desenvolvidas na área comportamental da contabilidade. Advances in Scientific and Applied Accounting, 10(1), 54-72. https://doi.org/10.14392/ASAA.2017100104

Deci, E. L., Connell, J. P., \& Ryan, R. M. (1989). Self-determination in a work organization. Journal of Applied Psychology, 74(4), 580-590. https://doi.org/10.1037/0021-9010.74.4.580

Deci, E. L., Olafsen, A. H., \& Ryan, R. M. (2017). Selfdetermination theory in work organizations: The state of a science. Annual Review of Organizational Psychology and Organizational Behavior, 4, 19-43. https://doi.org/10.1146/annurev-orgpsych-032516-113108

Deci, E. L., \& Ryan, R. M. (1985). Intrinsic motivation and selfdetermination in human behavior. New York: Springer.

Deci, E. L., \& Ryan, R. M. (2000). The "what" and "why" of goal pursuits: Human needs and the self-determination of behavior. Psychology Inquiry, 11(4), 227-268. https://doi.org/10.1207/S15327965PLI1104 01
Derfuss, K. (2009). The relationship of budgetary participation and reliance on accounting performance measures with individual-level consequent variables: A metaanalysis. European Accounting Review, 18(2), 203-239. http://doi.org/10.1080/09638180802652371

Derfuss, K. (2016). Reconsidering the participative budgetingperformance relation: A meta-analysis regarding the impact of level of analysis, sample selection, measurement, and industry influences. The British Accounting Review, 48(1), 17-37. https://doi.org/10.1016/j.bar.2015.07.001

Djalil, M.A., Indriani, M., \& Muttaqin, M. (2017). The influence of organizational commitment and motivation in the relationship between budget participation and managerial performance (empirical study on provincial government agencies (SKPA) of Aceh province, Indonesia), Brand Research in Accounting, Negotiation, and Distribution, 8, 12-24. Retrieved from https://www.edusoft.ro/brain/ index.php/brand/article/view/683

Faul, F., Erdfelder, E., Buchner, A., \& Lang, A.-G. (2009). Statistical power analyses using $\mathrm{G}^{*}$ Power 3.1: Tests for correlation and regression analyses. Behavior Research Methods, 41(4), 1149-1160. https://doi.org/10.3758/BRM.41.4.1149

Fornell, C., \& Larcker, D. F. (1981). Evaluating structural equation models with unobservable variables and measurement error. Journal of Marketing Research, 18(1), 39-50. https://doi.org/10.2307/3151312

Frezatti, F. (2009). Orçamento empresarial (5 ed.). São Paulo: Atlas.

Gómez-Miñambres, J. (2012). Motivation through goal setting. Journal of Economic Psychology, 33(6), 1223-1239. https://doi.org/10.1016/j.joep.2012.08.010

Gómez-Ruiz, L., \& Rodríguez-Rivero, E. (2018) The motivational role of consultative participation in a multi-period target setting: An experimental study. Spanish Journal of Finance and Accounting / Revista Española de Financiación y Contabilidad, 47(3), 329-351. https://doi.org/10.1080/02102412.2017.1371978

Groen, B., Wouters, M., \& Wilderom, C. (2017). Employee participation, performance metrics, and job performance: A survey study based on self-determination theory. Management Accounting Research, 36, 51-66. https://doi.org/10.1016/j.mar.2016.10.001

Hair, J. F., Anderson, R. E., Tatham, R. L., \& Black, W. C. (2009). Análise multivariada de dados (6 ed.). Porto Alegre: Bookman.

Hair, J. F., Hult, T. M., Ringle, C. M., \& Sarstedt, M. A. (2014). Primer on partial least squares structural equation modeling (PLS-SEM). Los Angeles: Sage Publications.

Hassel, L. G., \& Cunningham, G. M. (1993). Budget effectiveness in multinational companies: An empirical examination of environmental interaction on cognitive and affective effects of two dimensions of budgetary participation. Scandinavian Journal of Management, 9(4), 299-318. https://doi.org/10.1016/0956-5221(93)90026-O 
Hassel, L. G., \& Cunningham, G. M. (1996). Budget effectiveness in multinational corporations: an empirical test of the use of budget controls moderated by two dimensions of budgetary participation under high and low environmental dynamism. MIR: Management International Review, 36(3), 245-266. https://www.jstor.org/stable/40228360

Hayes, A.F. (2013). Introduction to mediation, moderation, and conditional process analysis: A regression-based approach. New York: The Guilford Press.

Isgiyarta, J., Nugroho, D. A., Ratmono, D., Helmina, M. R. A., \& Pamungkas, I. D. (2019). Budgetary participation on managerial performance: Commitment organization, innovation perception, and job relevant information as mediating variable. Quality - Access to Success, 20(173), 48-53. Retrieved from https://www.srac.ro/calitatea/en/ arhiva/2019/QAS Vol.20 No.173 Dec.2019.pdf

Jacomossi, F., Schlup, D., \& Zonatto, V. C da S. (2018). Efeitos da participação orçamentária na relação entre ambiguidade e conflito de papéis e o desempenho gerencial. Advances in Scientific \& Applied Accounting, 11(3), 391-409. http://doi.org/10.14392/ASAA.2018110302

Ke, W., \& Zhang, P. (2009). Motivations in open source software communities: The mediating role of effort intensity and goal commitment. International Journal of Electronic Commerce, 13(4), 39-66. https://doi.org/10.2753/JEC1086-4415130403

Kren,L. (1992). Budgetaryparticipationand managerial performance: The impact of information and environmental volatility. The Accounting Review, 67(3), 511-552. Retrieved from https://www.jstor.org/stable/247975

Kren, L., \& Liao, W. M. (1988). The role of accounting information in the control of organizations: A review of the evidence. Journal of Accounting Literature, 7(1), 280-309.

Kuvaas, B., Buch,R., Weibel,A., Dysvik,A., \&Nerstad,C.G.L.(2017). Do intrinsic and extrinsic motivation relate differently to employee outcomes? Journal of Economic Psychology, 61, 244-258. https://doi.org/10.1016/j.joep.2017.05.004

Kyj, L., \& Parker, R. J. (2008). Antecedents of budget participation: Leadership style, information asymmetry, and evaluative use of budget. ABACUS - A Journal of Accounting, Finances and Business Studies, 44(4), 423-442. https://doi.org/10.1111/j.1467-6281.2008.00270.x

Lau, C. M., \& Buckland, C. (2001). Budgeting-the role of trust and participation: A research note. Abacus, 37(3), 369388. https://doi.org/10.1111/1467-6281.00092

Lau, C. M., \& Tan, S. L. C. (2006). The effects of procedural fairness and interpersonal trust on job tension in budgeting, Management Accounting Research, 17(2), 171186. https://doi.org/10.1016/j.mar.2005.10.001

Lau, C. M., \& Roopnarain, K. (2014). The effects of nonfinancial and financial measures on employee motivation to participate in target setting. The British Accounting Review, 46(3), 228-247. https://doi.org/10.1016/j.bar.2014.02.006

Lavarda, C. E. F., \& Almeida, D. M. (2013). Budget participation and informational asymmetry: A study in a multinational company. Brazilian Business Review, 10(2), 74-96. https://doi.org/10.15728/bbr.2013.10.2.4
Lavarda, C.E.F., Sant'ana, S.V., Manfroi, L., \& Dagostini, L. (2015). Participação orçamentária e definição das metas orçamentárias em uma cooperativa agroindustrial. ConTexto, 15(30), 20-35. Retrieved from https://seer.ufrgs.br/ConTexto/article/view/43225

Locke, E. A., \& Latham, G. P. (1990). Work motivation and satisfaction: Light at the end of the tunnel. Psychological Science, 1(4), 240-246. https://doi.org/10.1111/j.1467-9280.1990.tb00207.x

Locke, E. A., \& Latham, G. P. (2002). Building a practically useful theory of goal setting and task motivation. American Psychologist, 57(9), 705-717. https://doi.org/10.1037//0003-066x.57.9.705

Locke, E. A., Motowidlo, S., \& Bobko, P. (1986). Using selfefficacy theory to resolve the conflict between goalsetting theory and expectancy theory in organizational behavior and industrial/organizational psychology. Journal of Social and Clinical Psychology, 4(3), 328-338. https://doi.org/10.1521/jscp.1986.4.3.328

Locke, E. A., \& Latham, G. P. (2004). What should we do about motivation theory? Six recommendations for the twentyfirst century. The Academy of Management Review, 29(3), 388-403. https://doi.org/10.2307/20159050

Lunardi, M. A., Zonatto, V. C. D. S., \& Nascimento, J. C. (2020). Mediating cognitive effects of information sharing on the relationshipbetweenbudgetaryparticipationandmanagerial performance. Revista Contabilidade \& Finanças, 31(82), 14-32. https://doi.org/10.1590/1808-057x201908610

Macinati, M. S., \& Rizzo, M. G. (2014). Budget goal commitment, clinical managers' use of budget information and performance. Health Policy, 117(2), 228-238. https://doi.org/10.1016/j.healthpol.2014.05.003

Maiga, A. S. (2005). Antecedents and consequences of budget participation. Advances in Management Accounting, 14, 211 231. https://doi.org/10.1016/S1474-7871(05)14010-6

Mathieu, J. E., \& Zajac, D. M. (1990). A review and meta-analysis of the antecedents, correlates, and consequences of organizational commitment. Psychological Bulletin, 108(2), 171-194. https://doi.org/10.1037/0033-2909.108.2.171

Meyer, J. P., Becker, T. E., \& Vandenberghe, C. (2004). Employee commitment and motivation: A conceptual analysis and integrative model. Journal of Applied Psychology, 89(6), 991-1007. https://doi.org/10.1037/0021-9010.89.6.991

Meyer, J. P., \& Herscovitch, L. (2001). Commitment in the workplace: Toward a general model. Human Resource Management Review, 11(3), 299-326. https://doi.org/10.1016/S1053-4822(00)00053-X

Mia, L. (1988). Managerial attitude motivation and the effectiveness of budget participation. Accounting, Organizations and Society,13(5), 465-475. https://doi.org/10.1016/0361-3682(88)90017-7

Mia, L. (1989). The impact of participation in budgeting and job difficulty on managerial performance and work motivation: A research note. Accounting, Organizations and Society, 14(4), 347-357. https://doi.org/10.1016/0361-3682(89)90005-6 
Milani, K. (1975). The relationship of participation in budgetsetting to industrial supervisor performance and attitudes: A field study. The Accounting Review, 50(2), 274-284. Retrieved from https://www.jstor.org/stable/244709

Mucci, D. M., Frezatti, F., \& Dieng, M. (2016). As múltiplas funçôes do orçamento empresarial. Revista de Administração Contemporânea, 20(3), 283-304. https://doi.org/10.1590/1982-7849rac2016140121

Murray, D. (1990). The performance effects of participative budgeting: An integration of intervening and moderating variables. Behavioral Research in Accounting, 2(2), 104-123. Retrieved from https://www.researchgate.net/publication/283918495

Nouri, H., \& Kyj, L. (2008). The effect of performance feedback on prior budgetary participative research using survey methodology: An empirical study. Critical Perspectives on Accounting, 19(8), 1431-1453. https://doi.org/10.1016/j.cpa.2007.11.003

Nouri, H., \& Parker, R. J. (1998). The relationship between budget participation and job performance: The roles of budget adequacy and organizational commitment. Accounting, Organizations and Society, 23(5-6), 467-483. https://doi.org/10.1016/S0361-3682(97)00036-6

Parker, R. J., \& Kyj, L. (2006). Vertical information sharing in the budgeting process. Accounting, Organizations and Society, 31(1), 27-45. https://doi.org/10.1016/j.aos.2004.07.005

Pinder, W. C. C. (2011). Work motivation in organizational behavior (2. ed.). New York: Psychology Press, Taylor \& Francis.

Podsakoff, P. M., MacKenzie, S. B., Lee, J.-Y., \& Podsakoff, N. P. (2003). Common method biases in behavioral research: A critical review of the literature and recommended remedies. Journal of Applied Psychology, 88(5), 879-903. https://doi.org/10.1037/0021-9010.88.5.879

Rachman, A. A (2014). The effect of organization commitment and procedural fairness on participative budgeting and its implication to performance moderating by management accounting information. Review of Integrative Business and Economics Research, 3(1), 201-218. Retrieved from: https://www.proquest.com/docview/1513215318

Reid, P. (2002). A critical evaluation of the effect of participation in budget target setting on motivation. Managerial Auditing Journal, 17(3), 122-129. https://doi.org/10.1108/02686900210419903

Revista Exame (2017, August). Melhores e maiores - As 1.000 maiores empresas do Brasil. Retrieved from https://exame. abril.com.br/revista-exame/1000-maiores-empresas/

Ryan, R. M., \& Deci, E. L. (2000). Self-determination theory and the facilitation of intrinsic motivation, social development and well-being. American Psychologist, 55(1), 68-78. http://doi.org/10.1037//0003-066x.55.1.68

Santos, A. C. D., Lavarda, C. E. F., \& Marcello, I. E. (2014). The relationship between cost management knowledge and budgetary participation with managers' performance. Revista Brasileira de Gestão de Negócios, 16(50), 124-142. http://doi.org/10.7819/rbgn.v16i50.1236
Sholihin, M., Pike, R. Mangena, M., \& Li, J. (2011). Goalsetting participation and goal commitment: Examining the mediating roles of procedural fairness and interpersonal trust in a UK financial services organization. The British Accounting Review, 43(2), 135-146. https://doi.org/10.1016/j.bar.2011.02.003

Shields, J. F., \& Shields, M.D. (1998). Antecedents of participative budgeting. Accounting, Organizations and Society, 23(1), 49-76. https://doi.org/10.1016/S0361-3682(97)00014-7

Stearns, J. J. P. (2016). The moderating effects of personality on the relationship between budget participation and motivation to reach the budget goal. International Journal of Business, Accounting, and Finance, 10(1), 144-165. Retrieved from https://www.iabpad.com/the-moderating-effectsof-personality-on-the-relationship-between-budgetparticipation-and-motivation-to-reach-the-budget-goal/

Subramaniam, N., \& Mia, L. (2001). The relation between decentralized structure, budgetary participation and organizational commitment: The moderating role of managers' value orientation towards innovation. Accounting, Auditing \& Accountability Journal, 14(1), 1230. http://doi.org/10.1108/09513570110381051

Vallerand, R. J. (1997). Toward a hierarchical model of intrinsic and extrinsic motivation. Advances in Experimental Social Psychology, 29, 271-360. https://doi.org/10.1016/S0065-2601(08)60019-2

Van der Kolk, B., Van Veen-Dirks, P. M. G, \& Bogt, H. J. T. (2019). The impact of management control on employee motivation and performance in the public sector. European Accounting Review, 28(5), 901-928. https://doi.org/10.1080/09638180.2018.1553728

Wafiroh, N. L., Abdani, F., \& Nurdin, F. (2020). Budget participation and budgetary slack: The mediating effect of autonomous budget motivation. Jurnal Akuntansi,10(3), 287-300. https://doi.org/10.33369/j.akuntansi.10.3.287-300

Welsh, D. T., Baer, M. D., Sessions, H., \& Garud, N. (2020). Motivated to disengage: The ethical consequences of goal commitment and moral disengagement in goal setting. Journal of Organizational Behavior, 41(7), 663-677. https://doi.org/10.1002/job.2467

Wentzel, K. (2002). The influence of fairness perceptions and goal commitment on managers' performance in a budget setting. Behavioral Research in Accounting, 14(1), 247-271. https://doi.org/10.2308/BRIA.2002.14.1.247

Wong-On-Wing, B., Guo, L., \&Lui, G. (2010). Intrinsic and extrinsic motivation and participation in budgeting: Antecedents and consequences. Behavioral Research in Accounting, 22(2), 133-153. https://doi.org/10.2308/bria.2010.22.2.133

Zonatto, V.C.daS., Nascimento, J. C., Lunardi, M.A., \& Degenhart, L. (2020). Effects of budgetary participation on managerial attitudes, satisfaction, and managerial performance. Revista de Administração Contemporânea, 24(6), 532-549. https://doi.org/10.1590/1982-7849rac2020200047

Zonatto, V. C. S., Weber, A., \& Nascimento, J. C. (2019). Efeitos da participação orçamentária na assimetria informacional, estresse ocupacional e desempenho gerencial. Revista de Administração Contemporânea, 23(1), 67-91. https://doi.org/10.1590/1982-7849rac2019170327 


\section{Autoria}

\section{Daniele Cristina Bernd*}

Universidade Federal de Santa Catarina, Programa de Pósgraduação em Contabilidade

Rua Roberto Sampaio Gonzaga, no 274, Trindade, 88040-380, Florianópolis, SC, Brasil.

E-mail: dcbernd@hotmail.com

(D) https://orcid.org/0000-0002-9195-9510

\section{Ilse Maria Beuren}

Universidade Federal de Santa Catarina, Programa de Pósgraduação em Contabilidade

Rua Roberto Sampaio Gonzaga, no 274, Trindade, 88040-380, Florianópolis, SC, Brasil.

E-mail: ilse.beuren@gmail.com

(D) https://orcid.org/0000-0003-4007-6408

\section{Celliane Ferraz Pazetto}

Universidade Federal de Santa Catarina, Programa de Pósgraduação em Contabilidade

Rua Roberto Sampaio Gonzaga, no 274, Trindade, 88040-380, Florianópolis, SC, Brasil.

E-mail: cellianeferraz@gmail.com

(D) https://orcid.org/0000-0002-7413-1981

\section{Carlos Eduardo Facin Lavarda}

Universidade Federal de Santa Catarina, Programa de Pósgraduação em Contabilidade

Rua Roberto Sampaio Gonzaga, no 274, Trindade, 88040-380, Florianópolis, SC, Brasil.

E-mail: eduardo.lavarda@ufsc.br

(D) https://orcid.org/0000-0003-1498-7881

* Autora Correspondente

\section{Financiamento}

Os autores relataram que não houve suporte financeiro para pesquisa deste artigo.

\section{Conflito de Interesses}

Os autores informaram que não há conflito de interesses.

\section{Verificação de Plágio}

A RAC mantém a prática de submeter todos os documentos aprovados para publicação à verificação de plágio, mediante o emprego de ferramentas específicas, e.g.: iThenticate.

\section{Direitos Autorais}

A RAC detém os direitos autorais deste conteúdo.

\section{Contribuições dos Autores}

$1^{a}$ autora: conceituaçáo (liderança); curadoria de dados (igual); análise formal (igual); investigação (igual); metodologia (liderança); administração de projeto (igual); validaçáo (liderança); visualizaçáo (igual); escrita - rascunho original (igual); escrita - revisão e edição (liderança).

$2^{a}$ autora: conceituação (igual); curadoria de dados (suporte); análise formal (igual); investigação (igual); metodologia (igual); administração de projeto (liderança); software (suporte); supervisão (liderança); validação (igual); visualização (igual); escrita - rascunho original (suporte); escrita - revisão e edição (liderança).

$3^{a}$ autora: conceituação (igual); curadoria de dados (liderança); investigação (igual); metodologia (igual); software (igual); validação (igual); visualização (igual); escrita - rascunho original (igual); escrita - revisão e ediçãoo (suporte).

$4^{\circ}$ autor: conceituação (igual); análise formal (igual); investigação (igual); metodologia (suporte); administração de projeto suporte); supervisão (suporte); visualização (suporte); escrita - rascunho original (suporte); escrita revisão e edição (suporte).

\section{Método de Revisão por Pares}

Este conteúdo foi avaliado utilizando o processo de revisão por pares duplo-cego (double-blind peer-review). A divulgação das informaçóes dos pareceristas constantes na primeira página e do Relatório de Revisão por Pares (Peer Review Report) é feita somente após a conclusão do processo avaliativo, e com o consentimento voluntário dos respectivos pareceristas e autores.

\section{Disponibilidade dos Dados}

Os autores optaram por não compartilhar a sua base de dados, e afirmam que o fazem tendo em vista que na carta de apresentaçáo da pesquisa foi assegurado aos sujeitos da pesquisa amplo sigilo e privacidade de suas respostas e demais informaçóes que permitissem associá-los aos seus cargos e empresas.

A RAC incentiva o compartilhamento de dados mas, por observância a ditames éticos, não demanda a divulgação de qualquer meio de identificação de sujeitos de pesquisa, preservando a privacidade dos sujeitos de pesquisa. A prática de open data é viabilizar a reproducibilidade de resultados, e assegurar a irrestrita transparência dos resultados da pesquisa publicada, sem que seja demandada a identidade de sujeitos de pesquisa. 


\section{APÊNDICE A.}

Tabela A1. Instrumento de pesquisa.

\begin{tabular}{|c|c|c|c|c|c|c|c|c|}
\hline Construto & Itens & Descrição & Carga & Média & DP & AVE & $\begin{array}{l}\text { Alfa de } \\
\text { Cronbach }\end{array}$ & $\begin{array}{l}\text { Conf. } \\
\text { composta }\end{array}$ \\
\hline \multirow{6}{*}{ 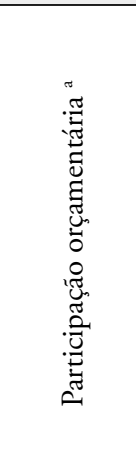 } & $\mathrm{CO} 1$ & $\begin{array}{l}\text { Nível de influência que você exerce no orçamento } \\
\text { final da sua área. }\end{array}$ & 0,792 & \multirow{6}{*}{5,05} & \multirow{6}{*}{1,58} & \multirow{6}{*}{0,649} & \multirow{6}{*}{0,891} & \multirow{6}{*}{0,917} \\
\hline & $\mathrm{CO} 2$ & $\begin{array}{l}\text { Parcela do seu envolvimento na elaboraçáo do } \\
\text { orçamento. }\end{array}$ & 0,827 & & & & & \\
\hline & $\mathrm{CO} 3$ & A importância da sua contribuição para o orçamento. & 0,731 & & & & & \\
\hline & IO1 & $\begin{array}{l}\text { Frequência de discussões relacionadas ao orçamento } \\
\text { iniciadas pelos supervisores. }\end{array}$ & 0,791 & & & & & \\
\hline & IO2 & $\begin{array}{l}\text { Frequência de discussōes relacionadas com o } \\
\text { orçamento iniciadas por você. }\end{array}$ & 0,853 & & & & & \\
\hline & IO3 & $\begin{array}{l}\text { Tipo de justificativa dada a você quando o orçamento } \\
\text { é revisado. }\end{array}$ & 0,832 & & & & & \\
\hline \multirow{6}{*}{ 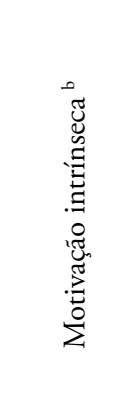 } & MINTR1 & $\begin{array}{l}\text { As tarefas que eu faço representam uma força motriz } \\
\text { (que impulsionam) no meu trabalho. }\end{array}$ & excluído & \multirow{6}{*}{5,47} & \multirow{6}{*}{1,31} & \multirow{6}{*}{0,718} & \multirow{6}{*}{0,883} & \multirow{6}{*}{0,91} \\
\hline & MINTR2 & As tarefas que eu faço no trabalho são agradáveis. & 0,826 & & & & & \\
\hline & MINTR3 & Meu trabalho é relevante. & excluído & & & & & \\
\hline & MINTR4 & Meu trabalho é muito empolgante. & 0,904 & & & & & \\
\hline & MINTR5 & $\begin{array}{l}\text { Meu trabalho é tão interessante que é uma motivação } \\
\text { por si só. }\end{array}$ & 0,908 & & & & & \\
\hline & MINTR6 & $\begin{array}{l}\text { Às vezes estou táo animado em meu trabalho que } \\
\text { praticamente esqueço de tudo ao meu redor. }\end{array}$ & 0,740 & & & & & \\
\hline \multirow{4}{*}{ 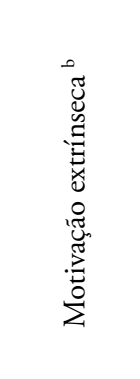 } & MEXTR1 & $\begin{array}{l}\text { Se eu preciso me empenhar mais no trabalho, eu } \\
\text { tenho que ganhar mais. }\end{array}$ & 0,810 & \multirow{4}{*}{2,95} & \multirow{4}{*}{1,72} & \multirow{4}{*}{0,638} & \multirow{4}{*}{0,738} & \multirow{4}{*}{0,839} \\
\hline & MEXTR2 & $\begin{array}{l}\text { É importante ter um incentivo externo para que eu } \\
\text { me motive em realizar um bom trabalho. }\end{array}$ & excluído & & & & & \\
\hline & MEXTR3 & $\begin{array}{l}\text { Incentivos externos como bônus e provisões } \\
\text { sáo essenciais para determinar o quáo bem eu } \\
\text { desempenho meu trabalho. }\end{array}$ & 0,688 & & & & & \\
\hline & MEXTR4 & $\begin{array}{l}\text { Se me oferecessem um salário melhor, eu teria feito } \\
\text { um trabalho melhor. }\end{array}$ & 0,885 & & & & & \\
\hline \multirow{4}{*}{ 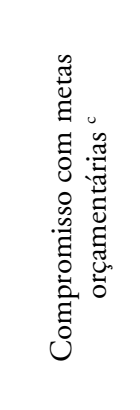 } & $\mathrm{CMO} 1$ & $\begin{array}{l}\text { Eu me importo em atingir as metas orçamentárias da } \\
\text { minha área. }\end{array}$ & 0,762 & \multirow{4}{*}{5,96} & \multirow{4}{*}{1,31} & \multirow{4}{*}{0,637} & \multirow{4}{*}{0,715} & \multirow{4}{*}{0,84} \\
\hline & $\mathrm{CMO} 2$ & $\begin{array}{l}\text { Custa-me muito abandonar as metas orçamentárias } \\
\text { da minha área. }\end{array}$ & 0,795 & & & & & \\
\hline & $\mathrm{CMO} 3$ & $\begin{array}{l}\text { Eu crio expectativas de atingir as metas orçamentárias } \\
\text { da minha área. }\end{array}$ & 0,835 & & & & & \\
\hline & $\mathrm{CMO} 4$ & $\begin{array}{l}\text { Dado que nem sempre se consegue dizer o quão } \\
\text { difícil é cumprir o orçamento, a menos que se tenha } \\
\text { trabalhado nele por algum tempo, é difícil levar a } \\
\text { sério as metas orçamentárias (R) }\end{array}$ & excluído & & & & & \\
\hline
\end{tabular}

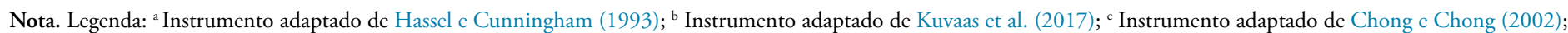
(R) Questáo reversa. Todos os construtos utilizaram escala tipo Likert de sete pontos (1 a 7), que variavam de: muito baixa/muito alta ${ }^{a}$; e discordo totalmente/concordo totalmente ${ }^{\mathrm{b}, \mathrm{c}}$. 